\title{
Molecular Mechanism of Enzymatic Chlorite Detoxification: Insights from Structural and Kinetic Studies
}

\author{
Irene Schaffner, ${ }^{\dagger}$ Georg Mlynek, $^{\dagger}{ }^{\dagger}$ Nicola Flego, ${ }^{\S}$ Dominic Pühringer, ${ }^{\ddagger}$ Julian Libiseller-Egger, ${ }^{\dagger}$
} Leighton Coates, "Stefan Hofbauer, ${ }^{\dagger}$ Marzia Bellei, ${ }^{\perp}$ Paul G. Furtmüller, ${ }^{\dagger}{ }^{\circ}$ Gianantonio Battistuzzi, ${ }^{\#}$ Giulietta Smulevich, ${ }^{\S}$ Kristina Djinović-Carugo, ${ }^{\ddagger}, \mathbb{I}$ and Christian Obinger* ${ }^{* \dagger} \dagger$

${ }^{\dagger}$ Department of Chemistry, Division of Biochemistry, BOKU-University of Natural Resources and Life Sciences, Muthgasse 18, A-1190 Vienna, Austria

${ }^{*}$ Department for Structural and Computational Biology, Max F. Perutz Laboratories, University of Vienna, Dr.-Bohr-Gasse 9, A-1030 Vienna, Austria

${ }^{\S}$ Dipartimento di Chimica "Ugo Schiff", Università di Firenze, Via della Lastruccia 3-13, I-50019 Sesto Fiorentino (FI), Italy

"Biology and Soft Matter Division, Oak Ridge National Laboratory, 1 Bethel Valley Road, Oak Ridge, Tennessee 37831, United States

${ }^{\perp}$ Department of Life Sciences, University of Modena and Reggio Emilia, Via Campi 103, 41125 Modena, Italy

\# Department of Chemistry and Geology, University of Modena and Reggio Emilia, Via Campi 103, 41125 Modena, Italy

${ }^{I}$ Department of Biochemistry, Faculty of Chemistry and Chemical Technology, University of Ljubljana, 1000 Ljubljana, Slovenia

Supporting Information

ABSTRACT: The heme enzyme chlorite dismutase (Cld) catalyzes the degradation of chlorite to chloride and dioxygen. Although structure and steady-state kinetics of Clds have been elucidated, many questions remain (e.g., the mechanism of chlorite cleavage and the $\mathrm{pH}$ dependence of the reaction). Here, we present high-resolution X-ray crystal structures of a dimeric Cld at $\mathrm{pH} 6.5$ and 8.5, its fluoride and isothiocyanate complexes and the neutron structure at $\mathrm{pH} 9.0$ together with the $\mathrm{pH}$ dependence of the $\mathrm{Fe}(\mathrm{III}) / \mathrm{Fe}$ (II) couple, and the UVvis and resonance Raman spectral features. We demonstrate that the distal Arg127 cannot act as proton acceptor and is fully ionized even at $\mathrm{pH} 9.0$ ruling out its proposed role in dictating the $\mathrm{pH}$ dependence of chlorite degradation. Stopped-flow

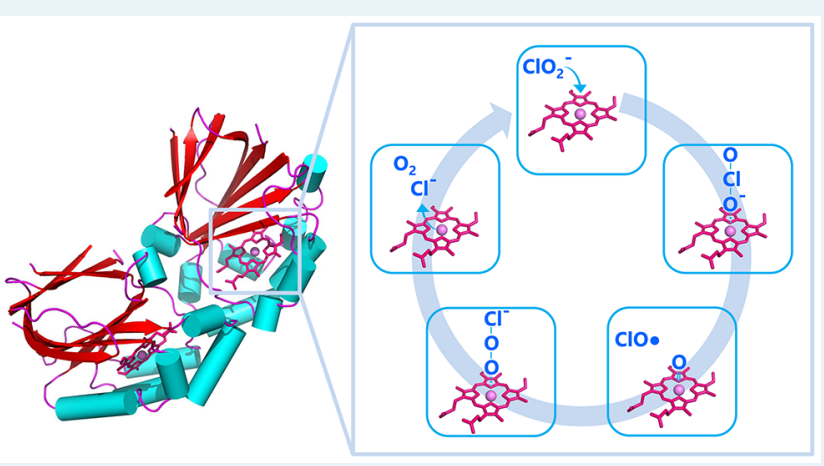
studies show that (i) Compound I and hypochlorite do not recombine and (ii) Compound II is the immediately formed redox intermediate that dominates during turnover. Homolytic cleavage of chlorite is proposed.

KEYWORDS: chlorite dismutase, heme enzyme, $\mathrm{O}_{2}$ generation, X-ray diffraction, neutron diffraction, stopped-flow spectroscopy, resonance Raman spectroscopy, spectroelectrochemistry

\section{INTRODUCTION}

Chlorite dismutases (Clds) are heme b-containing oxidoreductases (EC 1.13.11.49) found in prokaryotic organisms. ${ }^{1}$ They are able to efficiently decompose chlorite $\left(\mathrm{ClO}_{2}^{-}\right.$or $\left.\mathrm{OClO}^{-}\right)$into harmless chloride $\left(\mathrm{Cl}^{-}\right)$and dioxygen $\left(\mathrm{O}_{2}\right)$ with chlorite being the sole source of dioxygen. ${ }^{2}$ Thereby, a covalent oxygenoxygen bond is formed, a biochemical reaction that was believed to be unique to the water-splitting manganese complex of photosystem II of oxygenic organisms. ${ }^{3}$

The ability to degrade chlorite was shown for several functional (i.e., efficiently chlorite degrading) Clds, all of them possessing a putatively flexible arginine in an otherwise hydrophobic distal heme pocket. Available X-ray crystal structures reveal two distinct conformations, either pointing toward the heme iron ("in"; e.g., chlorite dismutase from Dechloromonas aromatica (DaCld), PDB: $3 \mathrm{Q} 08)^{4,5}$ or toward the substrate entry channel ("out"; e.g., chlorite dismutase from Nitrospira defluvii (NdCld), PDB: 3NN1). ${ }^{6}$

The mechanism of chlorite cleavage is still under discussion. Computational studies suggest homolytic cleavage of $\mathrm{OClO}^{-}$ thereby producing chlorine monoxide $\left(\mathrm{ClO}^{\bullet}\right)$ and Compound II $[$ Por $\cdots \mathrm{Fe}(\mathrm{IV})=\mathrm{O}]$, followed by a rebinding step and production of $\mathrm{Fe}$ (III)-peroxyhypochlorite that finally releases chloride and dioxygen (Reactions I and II). ${ }^{7}$ Binding of the anionic substrate chlorite $\left(\mathrm{p} K_{\mathrm{a}}=1.72^{8}\right)$ to ferric Cld is exergonic ${ }^{7}$ and independent of the Cld-typical arginine. ${ }^{9}$

Received: May 29, 2017

Revised: September 22, 2017

Published: October 13, 2017 


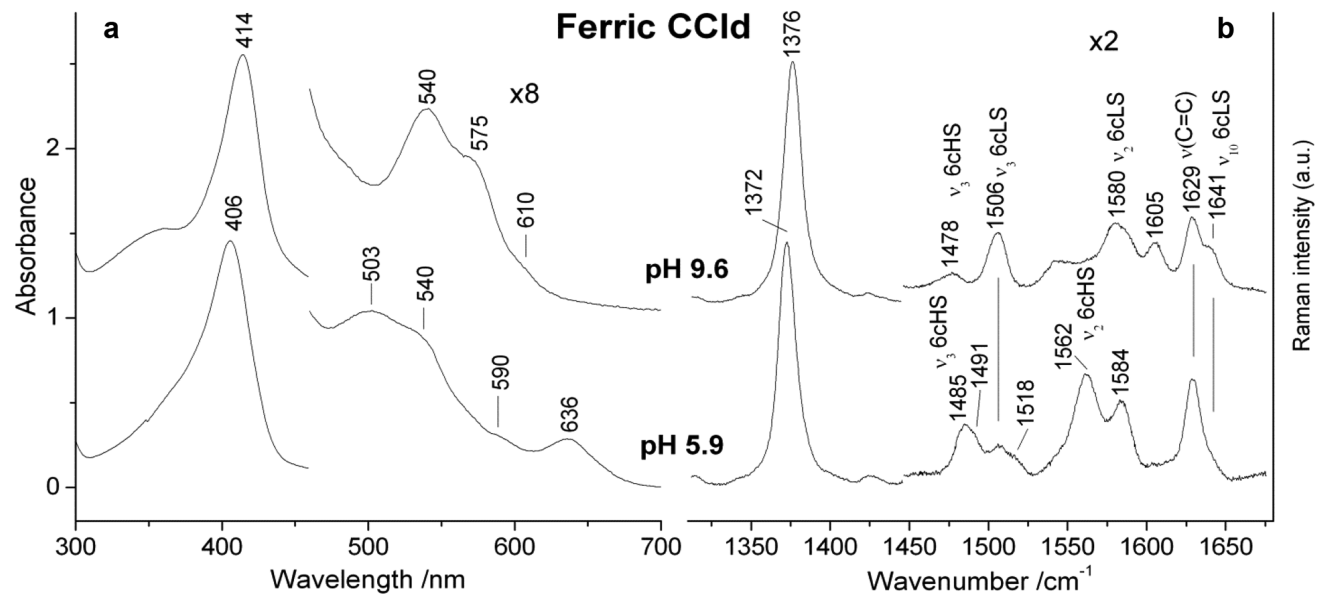

Figure 1. (a) Electronic absorption and (b) high-frequency RR spectra of ferric CCld at pH 5.9 and pH 9.6. Experimental conditions: UV-vis: (a) 600 $\mathrm{nm} / \mathrm{min}$ scan rate. The region between 450 and $700 \mathrm{~nm}$ has been expanded 8-fold. (b) RR: $413.1 \mathrm{~nm}$ exc., $5 \mathrm{~mW}$ laser power at the sample, and $10 \mathrm{~min}$ integration time. The region between 1450 and $1700 \mathrm{~cm}^{-1}$ has been expanded 2 -fold. The intensity of the spectra is normalized to that of the $\nu_{4}$ band.

$$
\begin{aligned}
& {\left[\text { Por } \cdots \mathrm{Fe}(\mathrm{III})-\mathrm{H}_{2} \mathrm{O}\right]+{ }^{-} \mathrm{OClO} \rightarrow\left[\mathrm{Por} \cdots \mathrm{Fe}(\mathrm{III})-{ }^{-} \mathrm{OClO}\right]} \\
& \quad \rightarrow\left[\mathrm{Por} \cdots \mathrm{Fe}(\mathrm{IV})=\mathrm{O} \cdots \mathrm{ClO}^{\bullet}\right] \\
& {\left[\text { Por } \cdots \mathrm{Fe}(\mathrm{IV})=\mathrm{O} \cdots{ }^{\circ} \mathrm{OCl}\right] \rightarrow\left[\text { Por } \cdots \mathrm{Fe}(\mathrm{III})-\mathrm{OOCl}^{-}\right]} \\
& \quad \rightarrow\left[\text { Por } \cdots \mathrm{Fe}(\mathrm{III})-\mathrm{H}_{2} \mathrm{O}\right]+\mathrm{O}_{2}+\mathrm{Cl}^{-}
\end{aligned}
$$

By contrast, biochemical studies on pentameric Clds suggest heterolytic cleavage of chlorite thereby forming Compound I $\left[\right.$ Por $\left.^{+} \cdot \ldots \mathrm{Fe}(\mathrm{IV})=\mathrm{O}\right]$ and hypochlorite $\left(\mathrm{HOCl} /{ }^{-} \mathrm{OCl}\right)$ (Reaction III). ${ }^{10-14}$ The following rebinding step produces $\mathrm{Fe}(\mathrm{III})-$ peroxyhypochlorite and, in consequence, chloride and dioxygen (Reaction IV).

$$
\begin{aligned}
& {\left[\text { Por } \cdots \mathrm{Fe}(\mathrm{III})-\mathrm{H}_{2} \mathrm{O}\right]+{ }^{-} \mathrm{OClO} \rightarrow\left[\mathrm{Por} \cdots \mathrm{Fe}(\mathrm{III})-{ }^{-} \mathrm{OClO}\right]} \\
& \quad \rightarrow\left[\operatorname{Por}^{+} \cdot \cdots \mathrm{Fe}(\mathrm{IV})=\mathrm{O} \cdots \mathrm{ClO}^{-}\right] \\
& {\left[\text {Por }^{+} \cdots \mathrm{Fe}(\mathrm{IV})=\mathrm{O} \cdots{ }^{-} \mathrm{OCl}\right] \rightarrow\left[\text { Por } \cdots \mathrm{Fe}(\mathrm{III})-\mathrm{OOCl}^{-}\right]} \\
& \quad \rightarrow\left[\text { Por } \cdots \mathrm{Fe}(\mathrm{III})-\mathrm{H}_{2} \mathrm{O}\right]+\mathrm{O}_{2}+\mathrm{Cl}^{-}
\end{aligned}
$$

In contrast to $K_{\mathrm{M}}$, the turnover number $\left(k_{\mathrm{cat}}\right)$ of Clds show a clear dependence on $\mathrm{pH}^{11}$ The $\mathrm{pH}$ optimum of chlorite degradation is typically in the acidic $\mathrm{pH}$ range, and the turnover number decreases with rising $\mathrm{pH}$. It has been postulated that the $\mathrm{pH}$ dependence of this reaction reflects the protonation state of the strictly conserved flexible distal arginine, which was reported to possess a $\mathrm{pK} K_{\mathrm{a}}$ of $\sim 6.5$ in $\mathrm{DaCld}^{14}$ and $\mathrm{NdCld}^{11}{ }^{11}$ both clade 1 members (see next paragraph). It was suggested that this basic amino acid supports both heterolytic cleavage of chlorite (Reaction III) and the recombination reaction between the postulated intermediate hypochlorite and Compound I (Reaction IV). Elimination of the distal Arg by mutation significantly decreases $k_{\text {cat }}$ and boosts the extent of irreversible inactivation. The latter event was proposed to be promoted by released hypochlorous acid, since scavengers of $\left(\mathrm{HOCl} /{ }^{-} \mathrm{OCl}\right)$ are able to suppress inactivation and increase the extent of degraded chlorite. ${ }^{11}$ It should be noted that the exclusiveness of such scavengers for $\left(\mathrm{HOCl} /{ }^{-} \mathrm{OCl}\right)$ is questionable, and it is not fully clear whether they would also detect chlorine monoxide or chlorine dioxide.

The known functional Clds can be divided into two phylogenetically distinct clades 1 and 2, which differ in subunit size and oligomerization. So far, biochemical and structural research has mainly focused on the pentameric and hexameric clade 1 proteins, ${ }^{6,10-17}$ whereas only few studies have addressed dimeric clade 2 Clds from Nitrobacter winogradskyi (NwCld), ${ }^{18}$ Klebsiella pneumonia MGH 78578 (KpCld), ${ }^{19}$ and Cyanothece sp. PCC7425 (CCld). ${ }^{20}$ The present study provides the first comprehensive structural and biochemical investigation of a dimeric clade 2 chlorite dismutase (i.e., CCld) and focuses on comprehensive structural and mechanistic studies including the impact of $\mathrm{pH}$ on chlorite conversion.

In contrast to pentameric Clds, the spectral features of CCld in various redox states are shown to be better resolved and easier to assign. We report the $\mathrm{pH}$ dependence of (i) the pre-steady-state kinetics of the reaction of ferric $\mathrm{CCld}$ with both $\mathrm{ClO}_{2}{ }^{-}$and the putative reaction intermediate $\left(\mathrm{HOCl} /{ }^{-} \mathrm{OCl}\right)$, (ii) the reduction potential of the $\mathrm{Fe}(\mathrm{III}) / \mathrm{Fe}$ (II) couple, and (iii) the UV-vis and resonance Raman spectra of the ferrous and ferric forms. We provide high-resolution X-ray structures of CCld at $\mathrm{pH} 6.5$ (1.30 $\AA$ ) and pH $8.5(1.55 \AA)$ as well as of its fluoride $(1.18 \AA)$ and isothiocyanate $(1.28 \AA$ ) complexes at $\mathrm{pH}$ 6.5. Moreover, we present the first neutron structure of a ferric heme enzyme from this superfamily solved at $\mathrm{pH} 9.0$ to a resolution of $2.35 \AA$ together with the $\mathrm{X}$-ray structure at room temperature. Our data demonstrate that the distal Arg is protonated at $\mathrm{pH} 9.0$ and indicate that $\mathrm{ClO}^{\circ}$ is the product of chlorite cleavage, at least in the $\mathrm{O}_{2}$ generative part of the reaction. This contradicts the hypothesis that the protonation state of the catalytic arginine modulates chlorite degradation.

On the basis of our data, we discuss the postulated mechanism(s) of chlorite conversion and provide a more detailed view of the mode of action including potential side reactions catalyzed by the enzyme.

\section{RESULTS}

2.1. Impact of $\mathrm{pH}$ on the Spectral Properties of Dimeric Ferric and Ferrous CCld. The electronic absorption and resonance Raman (RR) spectra of ferric CCld are presented in Figure 1. The electronic absorption spectrum at acidic $\mathrm{pH}$ (i.e., 5.9) of the ferric protein (Figure 1a, spectrum (i), characterized by a Soret band at $406 \mathrm{~nm}$, Q-bands at 503, 540, and $590 \mathrm{~nm}$, and a charge-transfer (CT1) band at $636 \mathrm{~nm}$, suggests a mixture of high-spin (HS) and low-spin (LS) species.

This is confirmed by the corresponding high-frequency RR spectrum (Figure 1b, bottom), which clearly indicates a mixture 


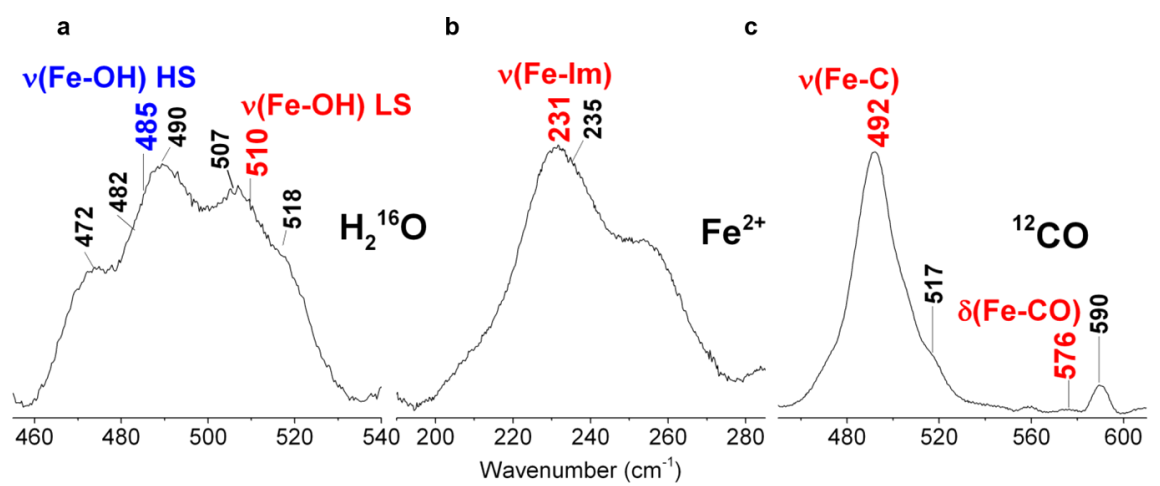

Figure 2. Low-frequency RR spectra of CCld. (a) ferric ( $\mathrm{pH}$ 9.6), (b) ferrous, and (c) ferrous- $\mathrm{CO}$ at $\mathrm{pH} 5.8$ showing the frequencies of the Fe-hydroxide LS, (red) and HS, (blue), Fe-Im, and the $\nu(\mathrm{Fe}-\mathrm{CO})$ stretching and $\delta(\mathrm{FeCO})$ modes, respectively. Experimental: $413.1 \mathrm{~nm}$ (ferric and CO complex) and $441.6 \mathrm{~nm}$ (ferrous) exc.; (a) $5 \mathrm{~mW}$ laser power at the sample, average of 12 spectra with $120 \mathrm{~min}$ integration time; (b) $11 \mathrm{~mW}$ laser power at the sample, 2 spectra with $20 \mathrm{~min}$ integration time; (c) $5 \mathrm{~mW}$ laser power at the sample, average of 4 spectra with 40 min integration time.
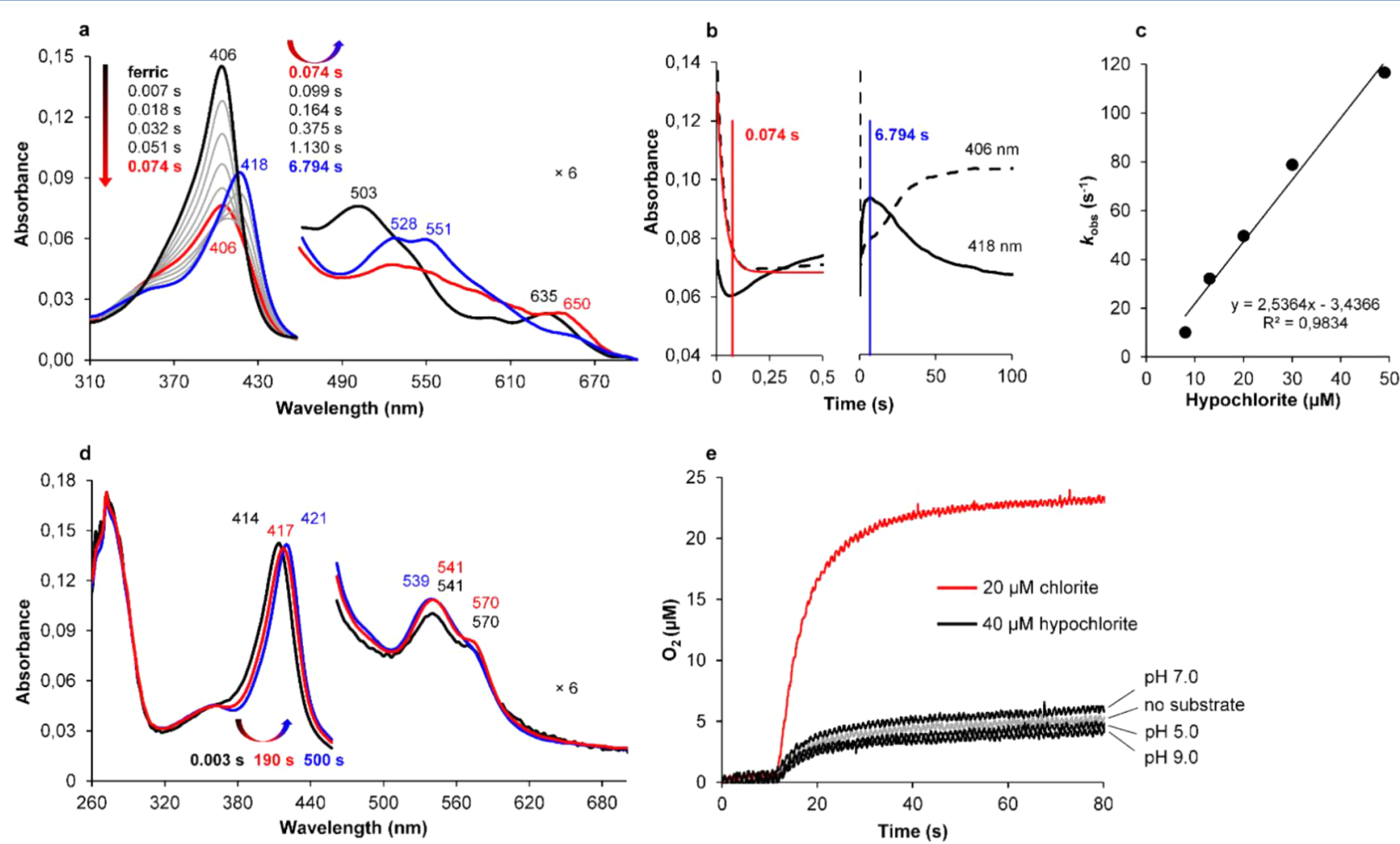

Figure 3. Reaction of ferric CCld with hypochlorite ( $\left.\mathrm{HOCl} /{ }^{\circ} \mathrm{OCl}\right)$. (a) Spectral changes of $1.5 \mu \mathrm{M}$ CCld upon reaction with $13 \mu \mathrm{M}$ hypochlorite at $\mathrm{pH}$ 5.0. Black: ferric CCld; red: Compound I; blue: Compound II-like species. For better visualization of the CT and Q bands, the 460-700 nm region is magnified 6-fold. Arrows illustrate the course of the reaction by both their colors and directions. (b) Corresponding time traces at $406 \mathrm{~nm}$ (ferric Soret maximum) and $418 \mathrm{~nm}$ (Soret maximum of Compound II-like species). Left: Time traces between 0.0 and $0.5 \mathrm{~s}$. The single exponential fit of the time trace at $405 \mathrm{~nm}$ is shown in red. Right: Time traces over the total recording time. Recording time points of the intermediate spectra shown in (a) are labeled in corresponding colors. (c) Linear dependence of $k_{\mathrm{obs}}$ from hypochlorite concentrations at $\mathrm{pH}$ 5.0. The rate constant $k_{\mathrm{app}}$ was obtained from the slope of the linear regression. (d) Spectral changes of $1.5 \mu \mathrm{M}$ CCld upon reaction with $500 \mu \mathrm{M}$ hypochlorite at $\mathrm{pH} 9.0$. Black: ferric CCld; red and blue: intermediate spectra exhibiting ferric low-spin features. Peak maxima are labeled. (e) Reaction of $1.5 \mu \mathrm{M}$ CCld with $20 \mu \mathrm{M}$ chlorite at pH 5.0 (red) and with $40 \mu \mathrm{M}$ hypochlorite at $\mathrm{pH}$ 5.0, 7.0, and 9.0 (black) followed by polarographic measurements using a Clark-type electrode. The negative control (no substrate) is shown in gray and reflects the amount of oxygen that is introduced to the $\mathrm{O}_{2}$-free system by triggering the reaction with enzyme solution.

of three species; an aquo 6-coordinate (6c) HS $\left(\nu_{3}\right.$ at $1485 \mathrm{~cm}^{-1}$, $\nu_{2}$ at $\left.1562 \mathrm{~cm}^{-1}\right)$, a 5 -coordinate $(5 \mathrm{c}) \mathrm{HS}\left(\nu_{3}\right.$ at $\left.1491 \mathrm{~cm}^{-1}\right)$, and a $6 \mathrm{cLS}\left(\nu_{3}\right.$ at $1506 \mathrm{~cm}^{-1}, \nu_{10}$ at $\left.1641 \mathrm{~cm}^{-1}\right)$. Furthermore, ferric CCld is characterized by two coincident vinyl stretching modes at $1629 \mathrm{~cm}^{-1}$ as for myoglobin, which downshift to 1626 in the ferrous form (Figure S1b, spectrum a). The low-frequency RR spectrum (Figure S2, spectrum a) of ferric CCld at $\mathrm{pH} 5.8$ is characterized by intense bands at $370 \mathrm{~cm}^{-1}$, due to the propionyl bending modes, and at 413 and $435 \mathrm{~cm}^{-1}$ due to the vinyl bending modes.

Figure S3a,b depicts the UV-vis spectral changes of CCld as a function of $\mathrm{pH}$ between $\mathrm{pH} 3.0$ and 10.0, and $\mathrm{pH} 5.8$ and 12.0, respectively. The $\mathrm{pKa}$ of the alkaline transition (i.e., deprotonation of the distal water) was calculated to be $8.1 \pm 0.04$.

At alkaline $\mathrm{pH}$, the absorption spectrum (Figure 1a, top) becomes typical of a hydroxo-complex, characterized by a 


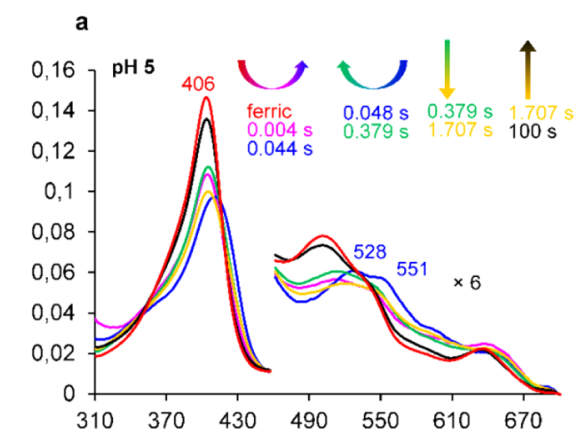

\section{b}
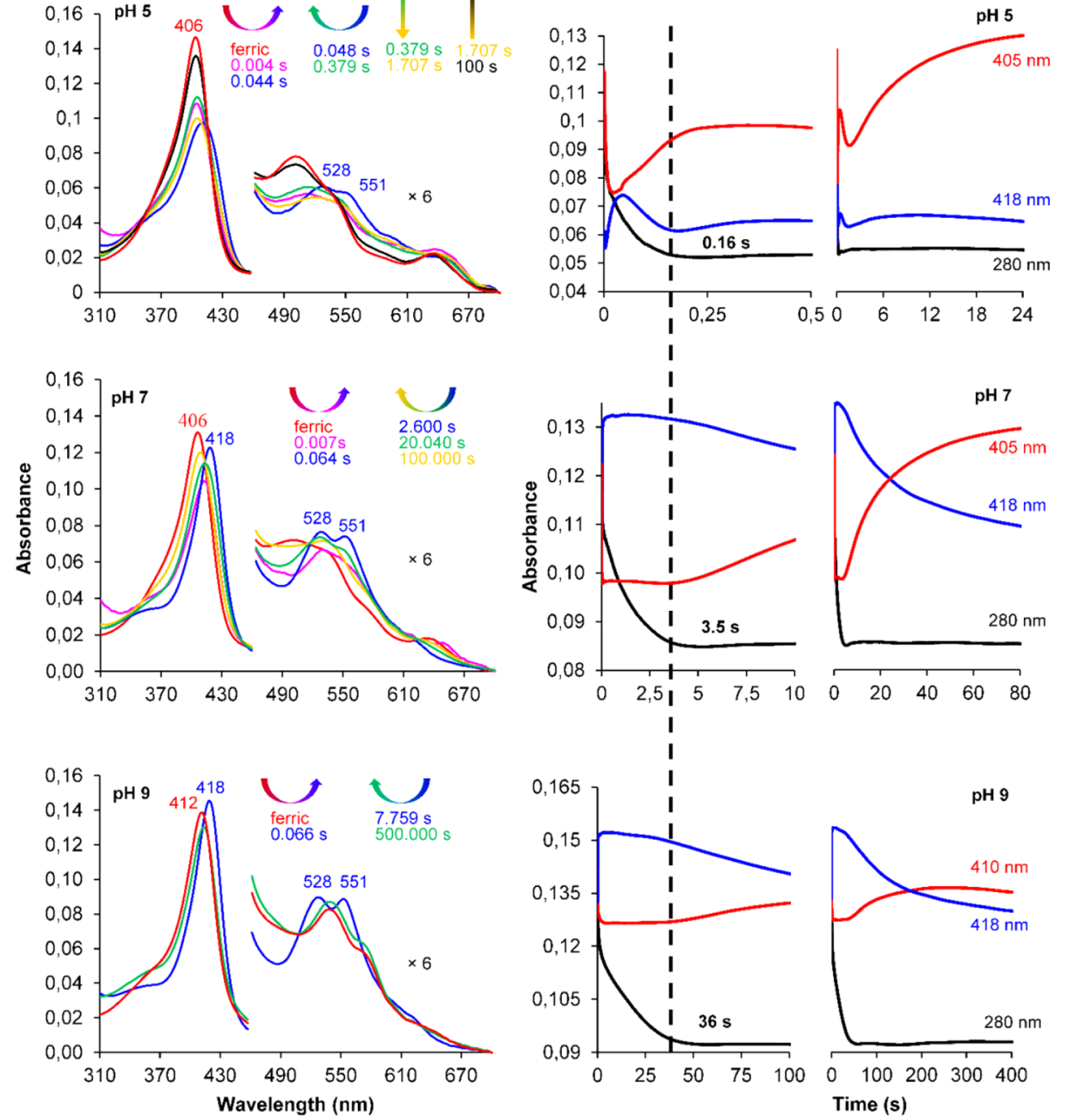

Figure 4. Reaction of ferric CCld with chlorite followed by UV-vis stopped-flow spectroscopy (top to bottom: pH 5.0, 7.0, 9.0). (a) Spectral changes of $1.5 \mu \mathrm{M}$ CCld upon reaction with $500 \mu \mathrm{M}$ chlorite. Spectrum of ferric CCld is shown in red, the dominating Compound II-like intermediate spectrum is depicted in blue. Peak maxima are labeled. For better visualization of the CT and Q bands, the $460-700 \mathrm{~nm}$ region is magnified 6-fold. Arrows indicate the course of the reaction by both, their colors and directions. Spectra and corresponding recording time points are shown in corresponding colors. (b) Corresponding time traces at: $405 \mathrm{~nm}(\mathrm{pH} 5.0$ and 7.0) and $410 \mathrm{~nm}$ (pH 9.0), ferric Soret maximum, red; $418 \mathrm{~nm}$, Soret maximum of the dominating Compound II-like intermediate species, blue; $280 \mathrm{~nm}$, chlorite decomposition, black. To emphasize the pH-dependent differences between the rates of chlorite degradation (time trace at $280 \mathrm{~nm}$ ), appropriate time frames are displayed in the left part of panel $(\mathrm{b}$ ), and the respective time points of completed chlorite decomposition are labeled and marked by the continuous dashed line.

mixture of $6 \mathrm{cHS}$ and $6 \mathrm{cLS}$ species with a Soret band at $414 \mathrm{~nm}, \mathrm{Q}$ bands at 540 and $575 \mathrm{~nm}$, and a weak CT1 band at $610 \mathrm{~nm}$. This is consistent with the high-frequency RR spectrum (Figure $1 \mathrm{~b}$, top) which displays a predominant 6cLS species $\left(\nu_{3} 1506, \nu_{2}\right.$ $\left.1580, \nu_{37} 1605, \nu_{10} 1641 \mathrm{~cm}^{-1}\right)$ and a weak $6 \mathrm{cHS}$ form $\left(\nu_{3} 1478\right.$ $\left.\mathrm{cm}^{-1}\right)$. Accordingly, in the low-frequency region the $\nu(\mathrm{Fe}-\mathrm{OH})$ stretching modes of the heme-hydroxide complexes have been identified by their sensitivity to ${ }^{2} \mathrm{H}$ and ${ }^{18} \mathrm{O}$ isotopic substitution (Figure S4a and Table S1) and on the basis of the difference spectra and curve fitting analysis (Figure S4b). The isotopic shifts observed for the ${ }^{18} \mathrm{O}$ and ${ }^{2} \mathrm{H}$ labeled species are in good agreement with those calculated using the diatomic harmonic oscillator model (Table S2). The LS and $\mathrm{HS} \nu(\mathrm{Fe}-\mathrm{OH})$ stretching modes have been assigned to the bands at the 510 and $485 \mathrm{~cm}^{-1}$, respectively (Figure 2a). It is noted that while the $6 \mathrm{cLS}$ is very similar to that found for DaCld and $\mathrm{KpCld}$ (514 and 509 $\mathrm{cm}^{-1}$, respectively), the $6 \mathrm{cHS}$ is more than $40 \mathrm{~cm}^{-1}$ higher (440 and $442 \mathrm{~cm}^{-1}$ in $\mathrm{DaCld}^{14}$ and $\mathrm{KpCld},{ }^{19}$ respectively).
The electronic absorption and RR spectra of the reduced protein clearly indicate the presence of a pure $5 \mathrm{cHS}$ state (Figure S1a,b, spectra (i)). It is noted that the spectrum of ferrous CCld is invariant in the $\mathrm{pH}$ interval 5.8-9.8 (data not shown). The low-frequency RR spectrum of ferrous 5cHS hemes is of interest particularly due to the presence of a strong band resulting from the iron-imidazole stretching mode, $\nu(\mathrm{Fe}-\mathrm{Im})$, in the range of $200-250 \mathrm{~cm}^{-1}$. The $\nu(\mathrm{Fe}-\mathrm{Im})$ frequency is very sensitive to $\mathrm{H}$ bonding interactions and, therefore, to the protein matrix surrounding the proximal His114 residue (CCld numbering). ${ }^{21,22}$ The intense band at $231 \mathrm{~cm}^{-1}$ observed for ferrous CCld at pH 5.8 (Figure 2b and Figure S2c) (higher than that observed for DaCld ${ }^{14}$ at $222 \mathrm{~cm}^{-1}$ but similar to that observed for $\left.\mathrm{KpCld}^{19}\right)$ is assigned to the $\nu(\mathrm{Fe}-\mathrm{Im})$ mode, a frequency somewhat higher than that observed in myoglobin $\left(220 \mathrm{~cm}^{-1}\right)$, where the proximal His is hydrogen bonded to a weak $\mathrm{H}$-bond acceptor.

2.2. Reactions of Ferric CCld with Hypochlorite. Hypochlorous acid is known to function as a two-electron 
oxidant that converts ferric peroxidases and catalases to the redox intermediate Compound I. ${ }^{23,24}$ In functional chlorite dismutases, the oxidation of ferric Cld by chlorite is proposed to transiently form hypochlorite (Reaction III) which is rapidly consumed in the subsequent recombination reaction (Reaction IV). Consequently, we asked whether ferric Cld can be oxidized by hypochlorite to Compound I followed by recombination of the latter with excess $\mathrm{OCl}^{-}$.

Thus, we followed the reaction of CCld with hypochlorite $\left(\mathrm{HOCl} /{ }^{-} \mathrm{OCl}, \mathrm{p} K_{\mathrm{a}}=7.53\right)$ spectrophotometrically using the stopped-flow technique (Figure $3 \mathrm{a}-\mathrm{d}$ ) and polarographically using a Clark-type electrode (Figure 3e). At pH 5.0, effective Compound I formation can be observed (Figure 3a, red spectrum) with an apparent second-order rate constant of 2.5 $\times 10^{6} \mathrm{M}^{-1} \mathrm{~s}^{-1}$ (Figure 3c).

For the depicted spectra and time traces at $\mathrm{pH} 5.0,1.5 \mu \mathrm{M}$ CCld and $13 \mu \mathrm{M}$ hypochlorite were used. After $0.074 \mathrm{~s}$, the Soret peak exhibits $50 \%$ hypochromicity, and a distinct band at $650 \mathrm{~nm}$ has emerged. Above a $\sim 6$-fold excess of hypochlorite, a slow shift of Compound I to a Compound II-like species (Soret maximum at $418 \mathrm{~nm}$ and $Q$ bands at 528 and $551 \mathrm{~nm}$ ) is observed (Figure 3a, blue spectrum). Finally, the enzyme slowly returns to the ferric resting state (Figure $3 \mathrm{~b}$, time trace at $406 \mathrm{~nm}$ ). The maximum abundance of the Compound II-like species is reached after $\sim 6.8 \mathrm{~s}$. At all hypochlorite concentrations tested, heme bleaching could be observed to some extent.

At $\mathrm{pH}$ 7.0, using the same concentrations of enzyme and substrate, Compound I formation is about 4 times faster $(9.6 \times$ $10^{6} \mathrm{M}^{-1} \mathrm{~s}^{-1}$, data not shown) compared to $\mathrm{pH}$ 5.0. However, it overlaps to a greater extent with the evolution of the Compound II-like species $(418,528$, and $551 \mathrm{~nm})$ which is already fully developed after $\sim 0.3 \mathrm{~s}$, approximately 23 times faster than at $\mathrm{pH}$ 5.0. At $\mathrm{pH}$ 9.0, the resting state of CCld exhibits a Soret band at $414 \mathrm{~nm}$ reflecting the presence of the $\mathrm{OH}^{-}$-complex described above. It does not directly react with hypochlorite. Only at higher concentration of oxidant, a very slow bathochromic shift is observed (Figure 3d). The final spectrum is similar to that of the CCld-cyanide complex. The nature of the ligand is unclear, one possibility is chlorate which can form upon disproportionation of hypochlorite. ${ }^{25}$ However, no spectral change could be observed upon incubation of CCld with chlorate at $\mathrm{pH} 9.0$ (data not shown).

Importantly, at no $\mathrm{pH}$ studied (i.e., $\mathrm{pH}$ 5.0, 7.0, and 9.0), could any $\mathrm{O}_{2}$ generation be observed polarographically upon mixing $1.5 \mu \mathrm{M}$ CCld with $40 \mu \mathrm{M}$ hypochlorite (Figure $3 \mathrm{e}$ ).

2.3. Chlorite Decomposition by Ferric CCld at Different pH Values. Recently we reported the steady-state kinetics of chlorite degradation of CCld and its $\mathrm{pH}$ dependence. ${ }^{20}$ The completeness of chlorite degradation as well as the initial reaction velocity increased with decreasing $\mathrm{pH}$. At $\mathrm{pH}$ 5.0, the chloritedegrading activity of CCld was found to have a $k_{\text {cat }}$ value of 1144 $\pm 23.8 \mathrm{~s}^{-1}$, a $K_{\mathrm{M}}$ of $162 \pm 10.0 \mu \mathrm{M}$, and a catalytic efficiency of $(7.1 \pm 0.6) \times 10^{6} \mathrm{M}^{-1} \mathrm{~s}^{-1}$. Reactions below $\mathrm{pH} 4.0$ could not be followed due to enzyme denaturation.

In the present work, we studied the $\mathrm{pH}$-dependent degradation of chlorite by CCld using UV-vis stopped-flow spectroscopy. For comparison, we kept the substrate/enzyme ratio constant at all $\mathrm{pH}$ values and chose a 330 -fold excess of chlorite, since this guaranteed full degradation of the oxidant over the whole range of $\mathrm{pH}$. We observed a significantly prolonged phase of chlorite decomposition with increasing $\mathrm{pH}$ (time traces at $280 \mathrm{~nm}$, Figure 4b). At pH 5.0, $500 \mu \mathrm{M}$ chlorite are degraded within $160 \mathrm{~ms}$ by $1.5 \mu \mathrm{M}$ CCld (Figure $4 \mathrm{~b}$, top). Within $\sim 40 \mathrm{~ms}$, the spectrum shifts to a (not entirely developed) Compound IIlike state (Figure 4a,b, top). At the very beginning of the reaction ( $\sim 4 \mathrm{~ms}$ after mixing), $\sim 25 \%$ hypochromicity and a shift of CT1 to $650 \mathrm{~nm}$ is observed, which might suggest Compound I formation to some extent. Higher substrate concentrations lead to immediate and full formation of Compound II (Soret maximum at $418 \mathrm{~nm}$, typical double peak at 528 and $551 \mathrm{~nm}$, Figure S5a). During chlorite degradation, this redox intermediate dominates and its spectrum is steadily converted to the ferric resting state. Interestingly, concomitant with chlorite degradation, an increase in absorbance at $360 \mathrm{~nm}$ is observed (Figure $\mathrm{S} 5 \mathrm{~b}, \mathrm{c})$. At this wavelength, chlorine dioxide exhibits its characteristic absorption maximum. ${ }^{26}$ From previous studies on horseradish peroxidase, ${ }^{24}$ it is known that this enzyme performs the classical peroxidase cycle upon reaction with chlorite, including Compound $\mathrm{I}$ and $\mathrm{HOCl} /{ }^{-} \mathrm{OCl}$ formation. Concomitantly, chlorite is used as one-electron donor for Compound I and Compound II which leads to generation of chlorine dioxide, the latter being monitored UV-vis spectroscopically and being responsible for heme destruction when present in excess. However, in the case of CCld, after consumption of all the chlorite $(0.160 \mathrm{~s})$, the absorbance at $360 \mathrm{~nm}$ decreases. The latter event is accompanied by a retransition to a Compound II-like spectrum which then very slowly shifts back to the ferric resting state.

At $\mathrm{pH} 7.0$, the degradation of $500 \mu \mathrm{M}$ chlorite by $1.5 \mu \mathrm{M}$ CCld takes $3.5 \mathrm{~s}$ (Figure 4a,b, middle). The spectral course of the reaction exhibits a direct and rapid transition of the resting state to fully developed Compound II (decrease in absorbance at 406 $\mathrm{nm}$ occurs simultaneously with red-shift of Soret maximum).

In contrast to $\mathrm{pH} \mathrm{5.0,} \mathrm{at} \mathrm{pH} 7.0$ there is no indication of Compound I formation and the spectral features of Compound II remain fully established during chlorite degradation. A very slow conversion to the ferric state starts as soon as all chlorite is consumed (isosbestic point at $413 \mathrm{~nm}$ ). The reaction at $\mathrm{pH} 9.0$ is qualitatively invariant compared to $\mathrm{pH} 7.0$, except that chlorite consumption proceeds over a longer time period (36 s) and no direct transition from Compound II to the resting state could be observed even after degradation of chlorite (Figure 4a,b, bottom). It is important to note that determination of apparent second-order rate constants for Compound II formation did not give reliable data. It was hampered by the fact that $k_{\text {obs }}$ values do not show any linear dependence on substrate concentrations below $\sim 66$-fold excess.

2.4. Spectral Properties of Ligand-Bound Ferric and Ferrous CCld. The ligand binding behavior of pentameric Clds has been probed extensively, ${ }^{14,27,28}$ and it has been shown that the use of different buffer compositions can produce a pronounced heterogeneity of high- and low-spin species. ${ }^{14,27}$ Interestingly, binding of LS ligands like cyanide does not necessarily render the enzyme inactive or alter the kinetic parameters of chlorite degradation. ${ }^{29}$ This is also the case for ferric CCld, which we probed for binding to the exogenous HSligand fluoride and the LS-ligand thiocyanate. The dissociation constants for both ligands were determined by titration, followed by UV-vis spectroscopy, to be $12.6 \mathrm{mM}$ for fluoride and 0.074 $\mathrm{mM}$ for thiocyanate (Figure S6).

Thiocyanate acts as a LS-ligand to the cofactor and binds in the form of isothiocyanate with its nitrogen atom oriented to the heme iron (q.v. Section 2.7). Accordingly, the presence of a lowspin heme is confirmed by a red-shifted Soret maximum at 414 $\mathrm{nm}$ and the intensity increase of Q-bands around 532 and 570 $\mathrm{nm}$ in the UV-vis spectrum (Figure S6a, dotted line). Fluoride 

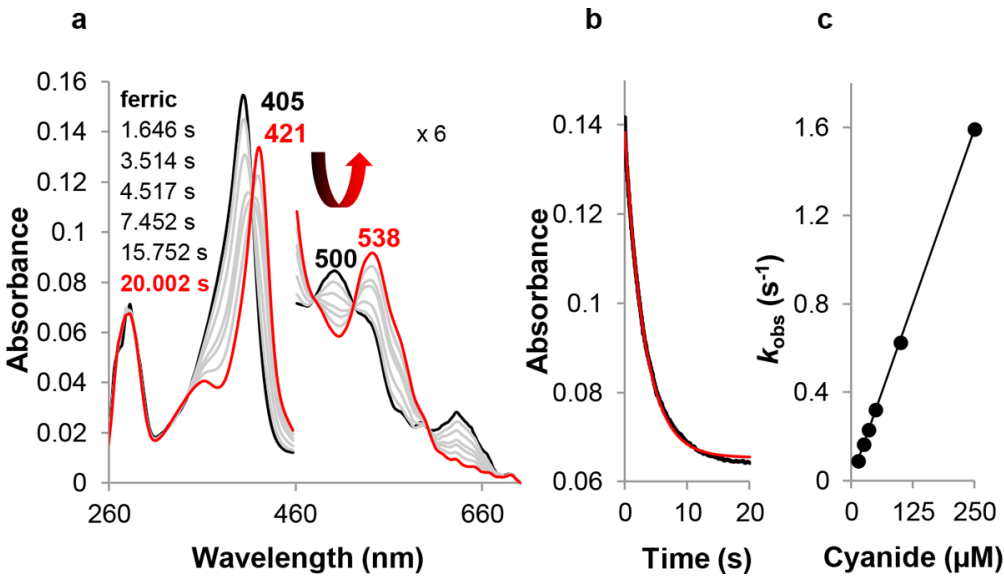

d

Figure 5. Binding of cyanide to ferric CCld. (a) Spectral changes during reaction of $1.5 \mu \mathrm{M}$ ferric CCld (black spectrum) with $35 \mu \mathrm{M}$ cyanide at pH 5.0. The red spectrum shows the emerging LS complex. The 460-700 $\mathrm{nm}$ region is magnified 6-fold. (b) Typical time trace at $405 \mathrm{~nm}$. The single exponential fit of the curve is depicted in red. (c) Plot of $k_{\mathrm{obs}}$ versus cyanide concentration. The apparent association constant $k_{\mathrm{on}}$ was obtained from the slope of the regression line. (d) Apparent bimolecular rate constants of cyanide binding to ferric CCld at pH 5.0, 6.0, 7.0, 8.0, 9.0, and 9.6 determined by UV-vis stopped-flow spectroscopy. Plot of $k_{\text {on }}$ versus $\mathrm{pH}$. The fit of the curve is depicted in red.

acts as HS-ligand; accordingly in the UV-vis spectrum, the Soret maximum is blue-shifted to $404 \mathrm{~nm}$, and strong bands at 503 and $611 \mathrm{~nm}$ are observed (Figure S6a, dashed line).

These features, and the high-frequency RR spectra obtained with $441.6 \mathrm{~nm}$ excitation $\left(\nu_{3}\right.$ at $1479 \mathrm{~cm}^{-1}, \nu_{2}$ at $1561 \mathrm{~cm}^{-1}, \nu_{10}$ at $1608 \mathrm{~cm}^{-1}$, data not shown), are characteristic of a $6 \mathrm{cHS}$ form, with fluoride coordinated as the sixth ligand of the iron ion. In the low-frequency $\mathrm{RR}$ spectra, the $\nu(\mathrm{Fe}-\mathrm{F})$ stretching mode was assigned on the basis of its intensity enhancement upon excitation near the CT2 band, ${ }^{30,31}$ as shown by the comparison of the RR spectra obtained with excitation at 413.1 and $441.6 \mathrm{~nm}$ (Figure S7a,b). The $\nu(\mathrm{Fe}-\mathrm{F})$ stretch is assigned to the band at $381 \mathrm{~cm}^{-1}$, which overlaps with the propionyl bending mode at $374 \mathrm{~cm}^{-1}$. The frequency is lower than the corresponding band of $\mathrm{KpCld}-\mathrm{F}$, and DaCld-F, complexes $\left(385,390 \mathrm{~cm}^{-1}\right.$, respectively). ${ }^{28}$ This result agrees very well with the trans-effect of the proximal ligand on the $\mathrm{Fe}-\mathrm{F}$ bond strength recently proposed for Clds. The higher the $\nu(\mathrm{Fe}-\mathrm{Im})$ frequency, the weaker the $\nu(\mathrm{Fe}-\mathrm{F})$ bond. ${ }^{28} \mathrm{CCld}$ has the largest trans-effect among the different Clds.

To further probe the ligand binding properties of CCld, carbon monoxide binding to the ferrous form of the enzyme was studied. Complex formation gives rise to a $6 \mathrm{cLS}$ species (Figure S1a,b, spectra (ii)). The $\nu_{3}$ band at $1470 \mathrm{~cm}^{-1}$ in the RR spectrum indicates the presence of a small amount of $5 \mathrm{cHS}$ ferrous heme due to photolysis of the CO ligand under laser irradiation. Unlike $\mathrm{DaCld},{ }^{14}$ the spectrum of the carbon monoxide complex is invariant in the $\mathrm{pH}$ interval 5.8-9.8 (data not shown). Figure S8 depicts the RR spectra of the ${ }^{12} \mathrm{CO}$ and ${ }^{13} \mathrm{CO}$ complexes of CCld in the low- and high-frequency regions. Figure $2 \mathrm{c}$ shows the two isotope sensitive bands at 492 and $576 \mathrm{~cm}^{-1}$ in ${ }^{12} \mathrm{CO}$ (which shift to 489 and $559 \mathrm{~cm}^{-1}$ for the CCld $-{ }^{13} \mathrm{CO}$ form, Figure S8a), assigned to the $\nu(\mathrm{Fe}-\mathrm{C})$ stretching and $\delta(\mathrm{Fe}-\mathrm{C}-\mathrm{O})$ bending modes, respectively. Accordingly, a corresponding $\nu(\mathrm{CO})$ stretching mode is observed at $1952 \mathrm{~cm}^{-1}$, which shifts to $1908 \mathrm{~cm}^{-1}$ for the ${ }^{13} \mathrm{C}$ labeled form (Figure $\mathrm{S} 8 \mathrm{~b})$. The $\nu(\mathrm{Fe}-\mathrm{C}) / \nu(\mathrm{CO})$ frequencies, similar to those previously found for $\mathrm{DaCld},{ }^{14}$ are typical of heme-CO adducts that have weak interaction with the distal protein matrix.

Finally, we probed the $\mathrm{pH}$ dependence of the kinetics of cyanide binding to CCld. Cyanide acts as a strong LS-ligand for many heme enzymes. For CCld, the spectral properties of the complex are qualitatively $\mathrm{pH}$-invariant and show a Soret maximum at $421 \mathrm{~nm}$, broad Q-bands with a maximum at 538 $\mathrm{nm}$, and a shoulder around $565 \mathrm{~nm} .^{20}$

In this work, binding rates have been determined by single exponential fitting of the decrease in absorbance at $405 \mathrm{~nm}(\mathrm{pH}$ 5.0, 6.0 and 7.0) or double exponential fitting of the increase in absorbance at 410 or $423 \mathrm{~nm}$ ( $\mathrm{pH} \mathrm{8.0,} \mathrm{9.0} \mathrm{and} \mathrm{9.6)} \mathrm{(Figure} \mathrm{S9).}$ At higher $\mathrm{pH}$ values, cyanide complexation is no longer the only reaction taking place since formation of the hydroxo-complex implies that $\mathrm{OH}^{-}$has to dissociate from the distal heme coordination site prior to $\mathrm{CN}^{-}$binding. Association constants increase with $\mathrm{pH}$ and range from $6.32 \times 10^{3} \mathrm{M}^{-1} \mathrm{~s}^{-1}$ at $\mathrm{pH} 5.0$ to $1.26 \times 10^{6} \mathrm{M}^{-1} \mathrm{~s}^{-1}$ at $\mathrm{pH} 9.0$ (Figure 5). Around $\mathrm{pH} 9.0$, the rate reaches a maximum and starts to decrease as the $\mathrm{pH}$ is raised further.

2.5. Impact of $\mathrm{pH}$ on the Standard Reduction Potential of the $\mathrm{Fe}(\mathrm{III}) / \mathrm{Fe}$ (II) Couple. Finally, we tested whether the pronounced $\mathrm{pH}$ dependence of the activity of CCld is related to $\mathrm{pH}$-dependent changes in redox properties. In order to determine the standard reduction potential $\left(E^{\circ \prime}\right)$ of the $\mathrm{Fe}(\mathrm{III}) / \mathrm{Fe}(\mathrm{II})$ couple of CCld, spectroelectrochemical studies were performed. Figure 6 shows the fully oxidized and fully
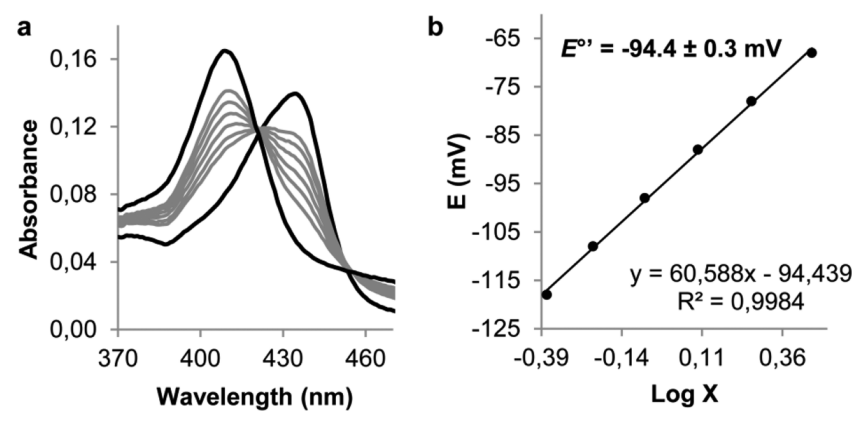

Figure 6. Spectroelectrochemical titration of the $\mathrm{Fe}(\mathrm{III}) / \mathrm{Fe}(\mathrm{II})$ redox couple of the high-spin native form of CCld (a) Electronic absorption spectra of CCld at different applied potentials at $\mathrm{pH}$ 6.0. Black lines represent fully oxidized $\left(A_{\lambda \text { ox }}{ }^{\text {Max }}\right.$ at $\left.406 \mathrm{~nm}\right)$ and fully reduced form $\left(A_{\lambda \text { red }}{ }^{\text {Max }}\right.$ at $\left.434 \mathrm{~nm}\right)$. (b) Nernst plot with $X$ representing $\left(A_{\lambda \text { red }}{ }^{\text {Max }}-\right.$ $\left.A_{\lambda \text { red }}\right) /\left(A_{\lambda_{\text {ox }}}\right.$ Max $\left.-A_{\lambda \text { ox }}\right)$. 


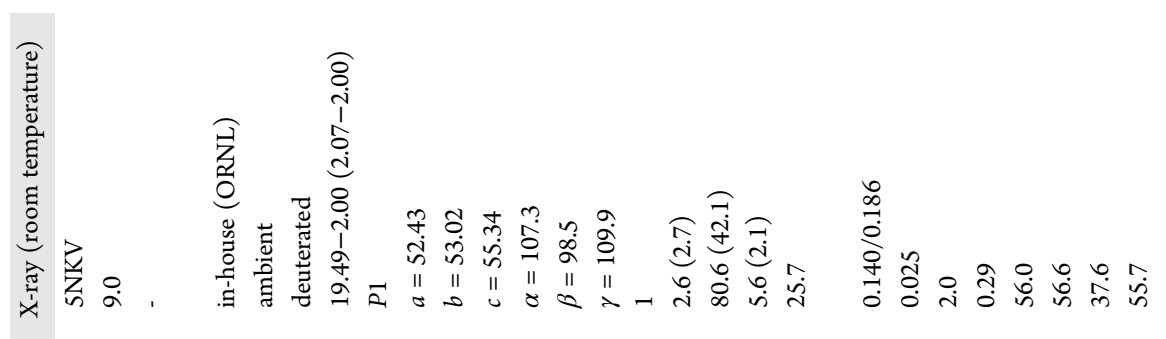

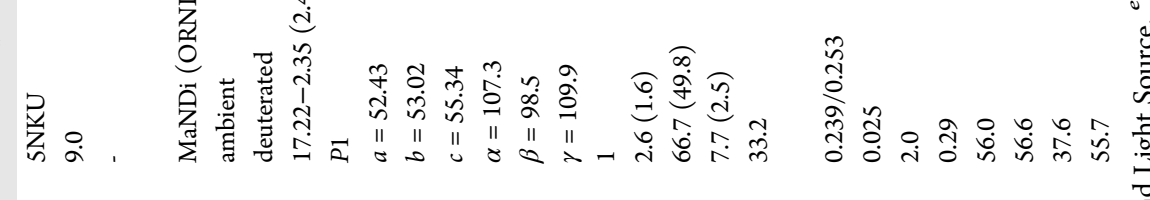

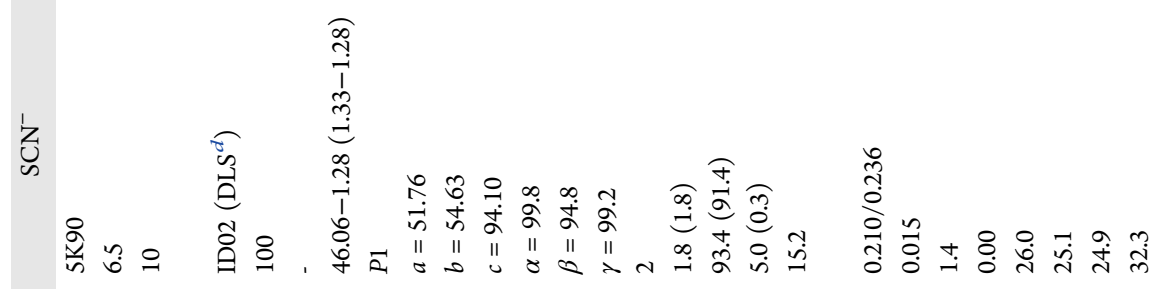

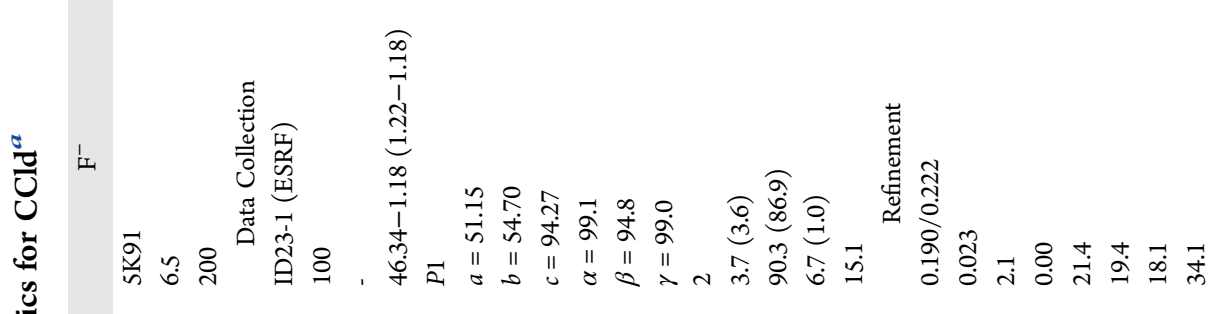

(⿸丆口

焉

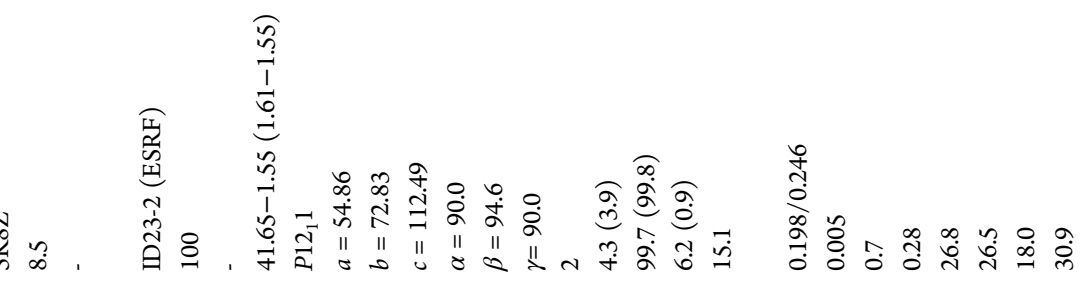

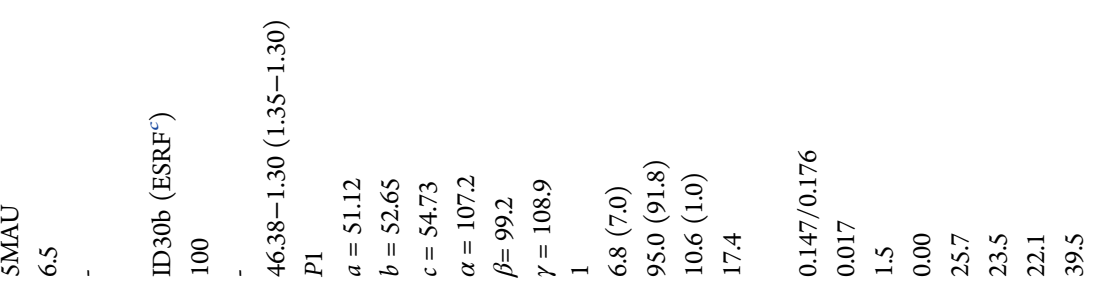

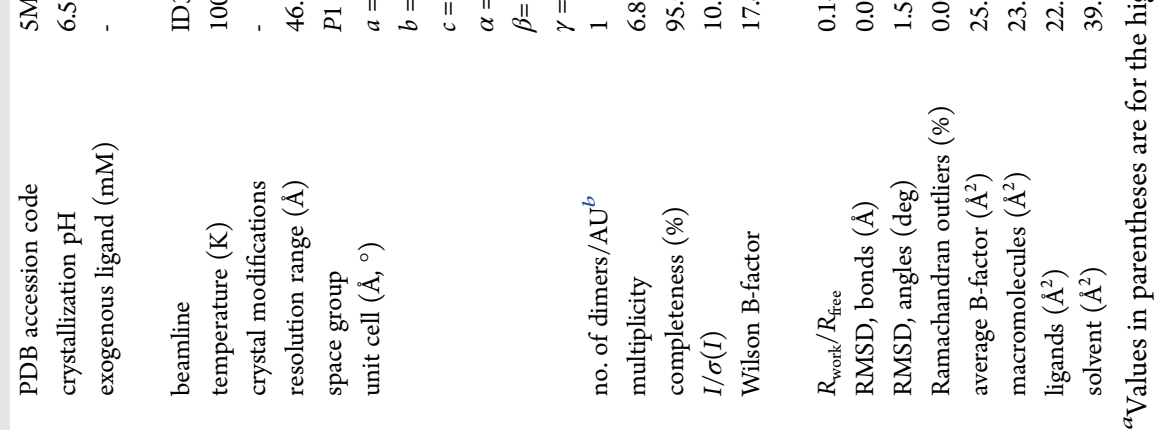


a

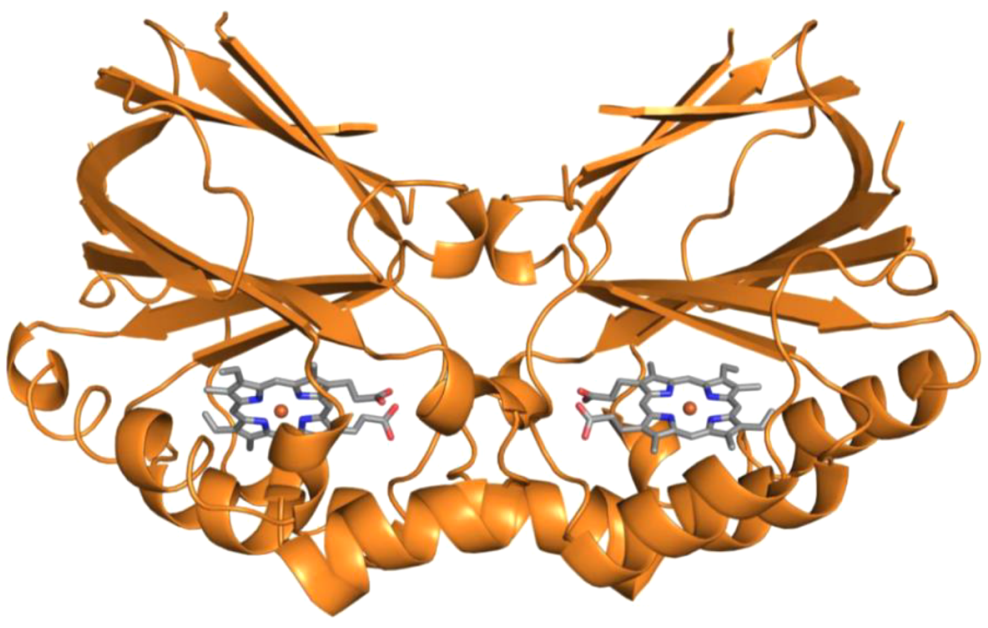

b
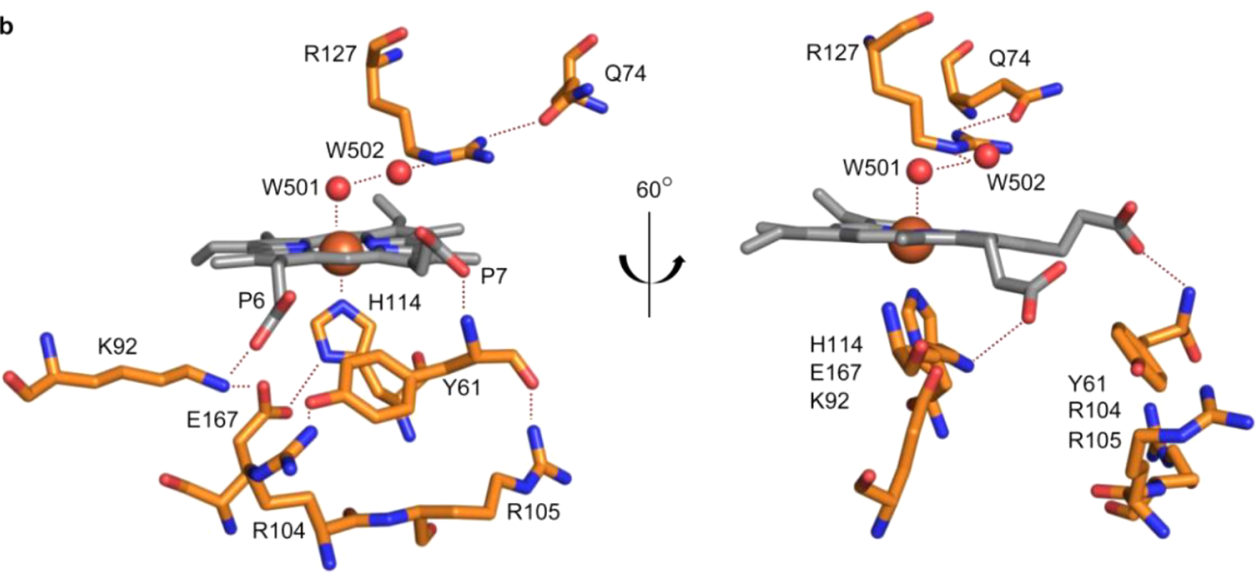

c
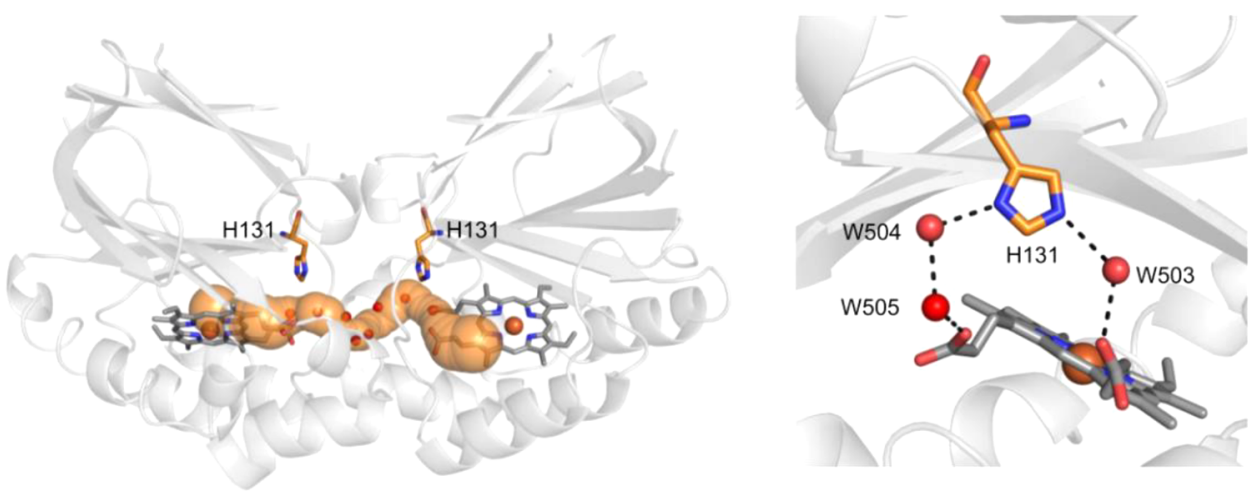

Figure 7. Structure of CCld crystallized at pH 6.5 (i.e., highly active state). (a) The dimeric structure is shown as cartoon. Heme groups are depicted as gray sticks, the heme iron is shown as an orange sphere. (b) Left: Detailed view of the active site surrounding amino acid residues. Distal residues include Q74 and R127, proximal residues include H114, E167, K92, Y61, R104, and R105, the latter three as well as the former three generating two hydrogen bonding networks via the heme propionates. Waters (W) and heme iron are depicted as red and orange spheres, respectively. The heme is shown as gray sticks. Dashed lines indicate hydrogen bonding distances which are listed in Table 2 . Right: Active site view rotated by $60^{\circ}$ for better visualization of the separation of the proximal hydrogen bonding networks. (c) Left: Illustration of a computed intramolecular tunnel (shown in orange) that is filled with water molecules (shown as red spheres) and generates an active-site connection. The side chains of H131 of both subunits are pointing toward this tunnel. Right: Zoom on H131 which is hydrogen bonded to waters W503, W504, and W505, thereby interconnecting the two heme propionate groups.

reduced (black lines, $A_{\lambda \text { ox }}{ }^{\text {Max }}=406 \mathrm{~nm}$ and $A_{\lambda \text { red }}{ }^{\text {Max }}=434 \mathrm{~nm}$ ) as well as the equilibrium spectra of CCld (gray lines) at six different applied potentials in the optically transparent thin-layer spectroelectrochemical (OTTLE) cell $\left(25^{\circ} \mathrm{C}, \mathrm{pH} 6.0\right)$. Two clear isosbestic points at 420 and $455 \mathrm{~nm}$ can be observed. From these data, we obtained a linear Nernst plot with a slope that is consistent with a one-electron reduction process (Figure 6b). ${ }^{32-34} E^{\circ \prime}$ was calculated to be $-94.4 \pm 0.3 \mathrm{mV}$.
Almost identical spectral transitions were observed at $\mathrm{pH} 5.0$ and 7.0 and from the corresponding Nernst plots $E^{\circ \prime}$ values were calculated to be $-82.5 \pm 0.9 \mathrm{mV}$ and $-126.3 \pm 1.9 \mathrm{mV}$, respectively (Figure $\mathrm{S} 10 \mathrm{a}-\mathrm{d}$ ). Between $\mathrm{pH} 5.0$ and 7.0, the reduction potential decreases by $-18.5 \mathrm{mV} / \mathrm{pH}$. At $\mathrm{pH} 10.0$, the establishment of a redox equilibrium between the $\mathrm{Fe}$ (III)hydroxo-complex $\left(A_{\lambda \text { ox }}{ }^{\text {Max }}=414 \mathrm{~nm}\right)$ and ferrous CCld $\left(A_{\lambda \text { red }}{ }^{\text {Max }}\right.$ $=434 \mathrm{~nm}$ ) was observed with an isosbestic point at $421 \mathrm{~nm}$. 
Table 2. Distance Analysis of Crystal Structures of Conserved Hydrogen Bonds in the Active Side of CCld ${ }^{a}$

\begin{tabular}{|c|c|c|c|c|c|c|c|}
\hline & & \multicolumn{6}{|c|}{ distance $(\AA)$} \\
\hline & & $\begin{array}{c}\mathrm{H}_{2} \mathrm{O} \\
(\mathrm{pH} 6.5)\end{array}$ & $\begin{array}{c}\mathrm{OH}^{-} \\
(\mathrm{pH} 8.5)\end{array}$ & $\mathrm{F}^{-}(\mathrm{pH} 6.5)$ & $\begin{array}{c}\mathrm{SCN}^{-} \\
(\mathrm{pH} 6.5)\end{array}$ & $\begin{array}{c}\text { neutron/X-ray } \\
(\mathrm{pH} \mathrm{9.0)}\end{array}$ & $\begin{array}{c}\text { X-ray room temperature } \\
(\mathrm{pH} \mathrm{9.0)}\end{array}$ \\
\hline \multirow[t]{5}{*}{$\operatorname{distal}^{b}$} & iron-ligand & $2.60 \pm 0.01$ & $2.51 \pm 0.06$ & $2.42 \pm 0.20$ & $2.04 \pm 0.01$ & $2.3 \pm 0.1$ & $2.5 \pm 0.1$ \\
\hline & ligand-W502 O & $2.87 \pm 0.06$ & $3.04 \pm 0.08$ & $2.91 \pm 0.09$ & $3.16 \pm 0.16$ & $3.0 \pm 0.2$ & $2.7 \pm 0.1$ \\
\hline & W502 O-127 $\mathrm{N}_{\varepsilon}$ & $2.91 \pm 0.04$ & $2.80 \pm 0.13$ & $2.95 \pm 0.01$ & $2.77 \pm 0.01$ & $2.6 \pm 0.0$ & $2.7 \pm 0.2$ \\
\hline & $127 \mathrm{~N}_{\eta} 1-74 \mathrm{O}_{\varepsilon} 1$ & $2.85 \pm 0.01$ & $2.84 \pm 0.08$ & $2.87 \pm 0.03$ & $2.85 \pm 0.08$ & $2.9 \pm 0.2$ & $3.1 \pm 0.1$ \\
\hline & $127 \mathrm{~N}_{\eta} 2-74 \mathrm{O}_{\varepsilon} 1$ & $2.98 \pm 0.01$ & $3.19 \pm 0.19$ & $3.02 \pm 0.02$ & $3.19 \pm 0.04$ & $3.5 \pm 0.1$ & $3.6 \pm 0.2$ \\
\hline \multirow[t]{4}{*}{ proximal $1^{c}$} & iron $-114 \mathrm{~N}_{\varepsilon} 2$ & $2.09 \pm 0.03$ & $2.30 \pm 0.03$ & $2.07 \pm 0.03$ & $2.11 \pm 0.01$ & $2.1 \pm 0.1$ & $2.4 \pm 0.1$ \\
\hline & $114 \mathrm{~N}_{\delta} 1-167 \mathrm{O}_{\varepsilon} 1$ & $2.77 \pm 0.04$ & $2.69 \pm 0.04$ & $2.77 \pm 0.03$ & $2.78 \pm 0.05$ & $2.8 \pm 0.0$ & $2.5 \pm 0.1$ \\
\hline & $167 \mathrm{O}_{\varepsilon} 2-92 \mathrm{~N}_{\zeta}$ & $2.74 \pm 0.02$ & $2.80 \pm 0.06$ & $2.73 \pm 0.01$ & $2.66 \pm 0.01$ & $2.6 \pm 0.0$ & $2.8 \pm 0.0$ \\
\hline & $92 \mathrm{~N}_{\zeta}-500 \mathrm{O} 1 / 2 \mathrm{D}$ & $2.76 \pm 0.01$ & $2.75 \pm 0.04$ & $2.78 \pm 0.01$ & $2.85 \pm 0.01$ & $2.8 \pm 0.1$ & $2.8 \pm 0.1$ \\
\hline \multirow[t]{5}{*}{ proximal $2^{d}$} & $500 \mathrm{O} 2 \mathrm{~A}-61 \mathrm{~N}$ & $2.80 \pm 0.02$ & $2.83 \pm 0.04$ & $2.81 \pm 0.01$ & $2.82 \pm 0.06$ & $2.8 \pm 0.0$ & $2.8 \pm 0.0$ \\
\hline & $61 \mathrm{O}-105 \mathrm{~N}_{\eta} 1$ & $2.92 \pm 0.02$ & $2.92 \pm 0.03$ & $2.91 \pm 0.04$ & $2.85 \pm 0.04$ & $3.0 \pm 0.0$ & $3.0 \pm 0.1$ \\
\hline & $104 \mathrm{~N}_{\eta} 1-61 \mathrm{OH}$ & $2.91 \pm 0.01$ & $2.93 \pm 0.02$ & $2.87 \pm 0.02$ & $2.90 \pm 0.01$ & $3.0 \pm 0.1$ & $2.9 \pm 0.0$ \\
\hline & $500 \mathrm{O} 1 \mathrm{D}-\mathrm{W} 506 \mathrm{O}$ & $2.65 \pm 0.00$ & $2.63 \pm 0.09$ & $2.63 \pm 0.03$ & $2.63 \pm 0.05$ & $2.6 \pm 0.1$ & $2.5 \pm 0.0$ \\
\hline & W506 O-61 OH & $2.63 \pm 0.04$ & $2.64 \pm 0.07$ & $2.63 \pm 0.04$ & $2.72 \pm 0.04$ & $2.6 \pm 0.1$ & $2.6 \pm 0.0$ \\
\hline
\end{tabular}

${ }^{a}$ [distance $(\AA) \pm$ standard deviation]. Standard deviation was calculated from all subunits in the AU. ${ }^{b}$ distal: heme iron-distal heme ligand -W502-Arg127-Gln74. ${ }^{c}$ proximal 1: heme iron-His114-Glu167-Lys92-propionate 6 (500 O1/2D). ${ }^{d}$ proximal 2: propionate 7 (500 O1/2A)Tyr61-Arg105-Arg104-Tyr61-propionate 7; propionate 7-Tyr61-W506-propionate 6.

From the linear Nernst plot, a standard reduction potential of $-172.7 \pm 1.5 \mathrm{mV}$ was obtained (Figure S10e,f).

2.6. X-ray Crystal Structure of CCld at pH 6.5 and 8.5. Homodimeric CCld crystallizes in space group $P 1$ or $P 12_{1} 1$ and the asymmetric unit contains one or two dimers, depending on the crystallization conditions (Table 1). Each subunit binds one heme $b$ and consists of a $\beta$-barrel that is made up of a threestranded and a five-stranded antiparallel $\beta$-sheet. Eight $\alpha$-helices complete the previously described ferredoxin-like fold (Figure $7 \mathrm{a}$ ) which represents the most prominent common feature of all heme binding (i.e., functional chlorite dismutase, DyP-type peroxidase, aldoxime dehydratase, IsdG, and coproheme decarboxylase) and nonheme-dependent superfamily members. Interactions between the enzyme subunits include a salt bridge (Arg64-Glu103), hydrogen bonds (Gln3-Asp134, Ile59-Arg104, Ala62-Asn101), and $\pi$-stacking (Trp97-Phe141-His131-Phe55) (Figure S11). The enzyme was crystallized in the presence of the endogenous ligands (i) $\mathrm{H}_{2} \mathrm{O}$ (i.e., at $\mathrm{pH}$ 6.5) and (ii) $\mathrm{OH}^{-}$(i.e., $\mathrm{pH} 8.5$ ), and the exogenous ligands (iii) thiocyanate (i.e., LSligand) and (iv) fluoride (i.e., HS-ligand). Crystals diffracted to high resolution [(i.e., $1.28 \AA$ for $\mathrm{SCN}^{-}, 1.18 \AA$ for $\mathrm{F}^{-}$bound CCld, $1.55 \AA$ for $\mathrm{OH}^{-}$bound CCld $(\mathrm{pH} 8.5)$ and $1.30 \AA$ for $\mathrm{H}_{2} \mathrm{O}$ bound CCld ( $\mathrm{pH} \mathrm{6.5)]} \mathrm{(Table} \mathrm{1).} \mathrm{All} \mathrm{of} \mathrm{them} \mathrm{are} \mathrm{structurally}$ very similar to a maximum rmsd value of $0.39 \AA$ over $340 \mathrm{C} \alpha$ atoms. Furthermore, the similarity to the only other solved dimeric chlorite dismutase structure of Nitrobacter winogradskyi is high with an rmsd of $0.81 \AA$ over 337 equiv $\mathrm{C} \alpha$ atoms. For both, NwCld and CCld, a very flexible loop, encompassing the residues 40 to 49 , could only be modeled in the $\mathrm{OH}^{-}$bound CCld structure (Figure S12c, the respective loops in both subunits are colored in red) due to special crystal packing which was the result of altered crystallization conditions (Figure S12a,b, pH 8.5 and 6.5, respectively).

Figure $7 \mathrm{~b}$ shows the active site architecture of CCld at $\mathrm{pH} 6.5$ (i.e., highly active state). His 114 serves as the proximal fifth heme ligand, and its $\mathrm{N}_{\varepsilon} 2$ is at a distance of $2.09 \AA$ from the iron atom. The distal sixth heme ligand $\mathrm{H}_{2} \mathrm{O}$ binds to the heme iron at a distance of $2.60 \AA$. This distance is longer than expected for a water molecule bound to the heme iron. As previously observed for the ARP/CIP-SHA complex, ${ }^{35}$ the combined analysis of the spectroscopic data and X-ray crystal structures of CCld at $\mathrm{pH} 6.5$ indicates that the $\mathrm{Fe}-\mathrm{H}_{2} \mathrm{O}$ distance as measured by X-ray diffraction is an average resulting from the $5 c$ and $6 c$ species in equilibrium that, however, are directly revealed by RR spectroscopy. Very importantly, it has to be noted, that the extent of photoreduction in the crystal is strongly dependent on the applied radiation dose, ${ }^{36}$ and it has been shown that the redox sensitive metal centers get significantly reduced at already $10 \%$ of applied dose needed to collect the entire diffraction data set. Thus, the heme iron is very likely fully reduced, which is most probably at the basis of the unexpected increased distance to the distal ligand since water does not usually bind to the ferrous heme iron. The distal ligand is in hydrogen bonding distance (i.e., $2.87 \AA$ ) to a conserved $\mathrm{H}_{2} \mathrm{O}$ molecule (W502) found in every CCld X-ray data set, notably also in the neutron and X-ray data sets collected at room temperature (q.v. Section 2.8). W502 is in turn H-bonded ( $2.91 \AA$ ) to the $\mathrm{N}_{\varepsilon}$ of $\operatorname{Arg} 127$ residue, which is strictly conserved among functional Clds. ${ }^{11,12}$ Interestingly, in all obtained CCld data sets, the Arg127 side chain is positioned away from the heme moiety. This out-conformation is putatively stabilized by hydrogen bonding between $\mathrm{N}_{\eta} 1$ of $\operatorname{Arg} 127$ and $\mathrm{O}_{\varepsilon} 1$ of Gln74 (2.85 $\AA$ ) (Figure 7b). For CCld, two separate hydrogen bonding networks on the proximal side of the heme can be identified. All involved residues (i.e., His114, Glu167, Lys92 and Tyr61, Arg104, Arg105) are conserved among functional chlorite dismutases with the exception of Arg105 which is characteristic for clade 2 representatives. As previously described, His114, Glu167, and Lys92 form an H-bonding network from the heme iron to the heme substituent propionate 6 (Figure $7 \mathrm{~b}$ ). ${ }^{12} \mathrm{~A}$ second network is generated by Tyr61, Arg104, and Arg105, which are interconnected via hydrogen bonds between their side chains. Tyr61 generates an additional hydrogen bond to propionate at position 7 via its backbone nitrogen (Figure $7 \mathrm{~b}$ ).

Further, two active site access channels per subunit can be identified. Since the subunits are rotated $180^{\circ}$ with respect to each other, just one connection from the surface to the active site per subunit remains, whereas the other one disappears in the protein interface (Figure $7 \mathrm{c}$ ). Using CAVER, ${ }^{37}$ it becomes evident that the latter channel interconnects both active sites (Figure $7 c$, left). CAVER reports an average bottleneck radius for 

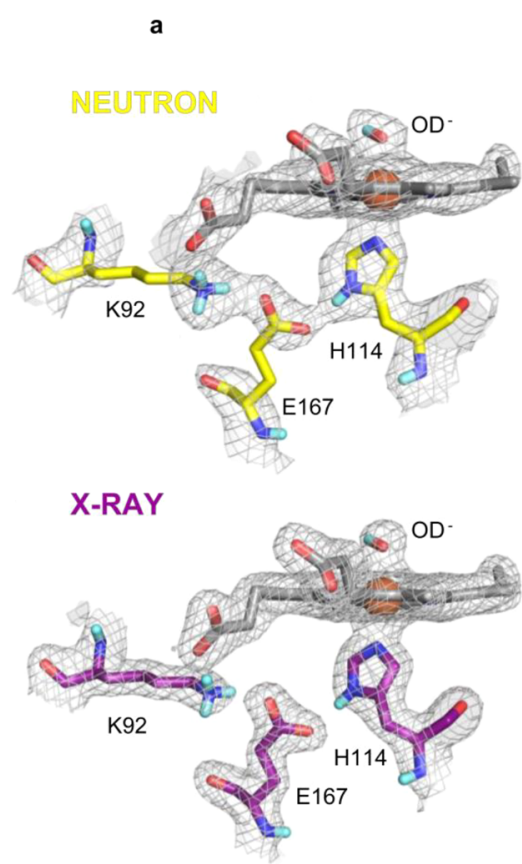

b

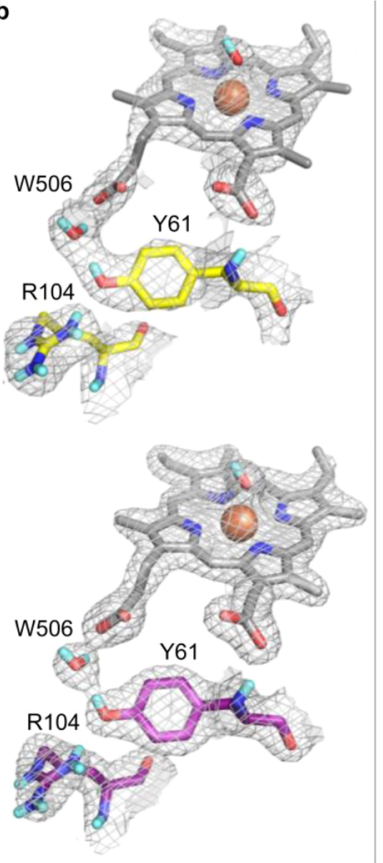

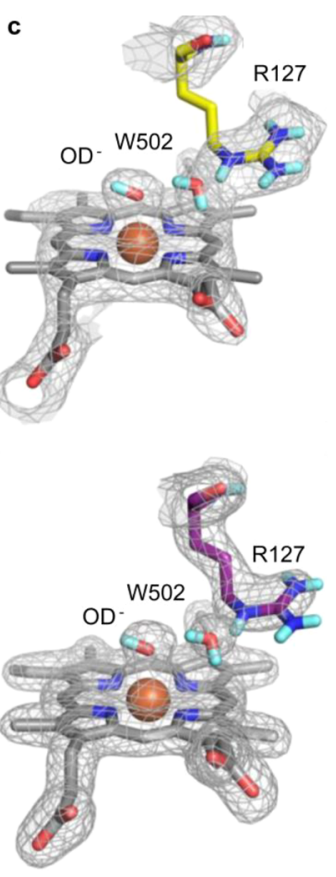

Figure 8. Comparison of neutron (yellow, $\sigma=1.4$ ) and X-ray (purple, $\sigma=1.5$ ) $2 F_{0}-F_{c}$ density maps in the active site of CCld at $\mathrm{pH}$ 9.0. (a) Proximal $\mathrm{H}$ bonding players His114, Glu167, and Lys92. (b) H-bonding network between Tyr61, a conserved deuterium atom (W506) and the heme propionate 6. (c) Catalytically important Arg127 with the side chain oriented toward the substrate entrance channel (out-conformation). The distal heme ligand OD ${ }^{-}$ is depicted as sticks, the heme iron is shown as an orange sphere. Nitrogen: blue, oxygen: red, deuterium: turquoise.

the tunnel of $1.43 \AA$. The channel is approximately $25 \AA$ in length (from propionate to propionate) and potentially enables a facilitated chemical cross-talk between CCld subunits.

Figure S12d shows the active site structure of CCld at $\mathrm{pH} 8.5$ (i.e., moderately active state). $\mathrm{N}_{\varepsilon} 2$ of His 114 is at a distance of $2.30 \AA$ from the coordinated iron atom of the heme group whereas the oxygen of $\mathrm{OH}^{-}$is at a distance of $2.51 \AA$. The aforementioned $\mathrm{H}_{2} \mathrm{O}$ (W502) is at $2.80 \AA$ from $\mathrm{N}_{\varepsilon}$ of $\operatorname{Arg} 127$. $\mathrm{N}_{\eta} 1$ of $\operatorname{Arg} 127$ is in hydrogen bonding distance (i.e., $2.84 \AA$ ) to $\mathrm{O}_{\varepsilon} 1$ of $\mathrm{Gln} 74$.

2.7. X-ray Crystal Structures of Fluoride and Isothiocyanate Complexes of CCld. Figure S13a shows the active site of CCld with the heme bound to fluoride. The protein was crystallized at $\mathrm{pH}$ 6.5, and the electron density map was contoured at $\sigma=1.6$. The distance of proximal histidine $\mathrm{N}_{\varepsilon} 2$ to the iron atom is $2.07 \AA$, and the high-spin ligand fluoride is at a distance of $2.42 \AA$ from the iron atom. W502 is at a distance of $2.91 \AA$ from the ligand and at a distance of $2.95 \AA$ from $\mathrm{N}_{\varepsilon}$ of Arg127, whose $\mathrm{N}_{\eta} 1$ is $2.87 \AA$ away from $\mathrm{O}_{\varepsilon} 1$ of Gln74 (Table 2). Also in this case, the unexpected increased distance between the iron atom and the fluoride is most probably a consequence of the photoreduction since fluoride binds only ferric hemes. ${ }^{30}$

Figure S13b shows the active site of CCld in complex with $\mathrm{SCN}^{-}$which was crystallized at $\mathrm{pH}$ 6.5. The distance of $\mathrm{N}_{\varepsilon} 2$ of His 114 to the iron atom is $2.11 \AA$. The LS-ligand $\mathrm{SCN}^{-}$binds with its nitrogen atom facing the heme iron at a distance of 2.04 $\AA$. W502 is at $3.16 \AA$ from the ligand nitrogen atom and $2.77 \AA$ distant from $\mathrm{N}_{\varepsilon}$ of $\operatorname{Arg} 127$. Once again, hydrogen bonding can be observed between $\mathrm{N}_{\eta} 1$ of $\operatorname{Arg} 127$ and $\mathrm{O}_{\varepsilon} 1$ of Gln74 at a distance of $2.85 \AA$. To confirm the depicted orientation of the ligand, a data set was collected at a wavelength of $1.9 \AA$ (Figure S13c) at which the anomalous scattering of nitrogen and carbon is negligible and the strong difference anomalous electron density peak corresponds to the sulfur atom, corroborating the orientation of the ligand. The data enable us to conclude that the sulfur does not directly interact with the iron atom.

2.8. Neutron and X-ray Crystal Structure of CCld at pH 9.0 and Room Temperature. Two of the most substantial limiting factors of using X-rays for protein structure determination are that (i) positions of hydrogens and protons, which contribute up to $50 \%$ or more to the total number of atoms in a protein, often cannot be determined from X-ray scattering data and (ii) photoreduction occurs, which is especially an issue for metal containing enzyme cofactors like heme. ${ }^{38}$ Neutrons are able to overcome both issues since neutrons (i) are scattered by hydrogen atoms to the same extent as as carbons, nitrogen or oxygen atoms and they (ii) are nonionizing. Consequently, photoreduction does not occur at all. ${ }^{39}$ Here, we used neutron crystallography as a complementary technique to X-ray diffraction studies to obtain comprehensive structural information on CCld in its active ferric state, including protonation states of important amino acid residues. In particular, the protonation state of this Arg is the subject of ongoing debate as it is believed that an untypically low $\mathrm{pK}_{\mathrm{a}}$ value (i.e., around 6.5 for $\mathrm{DaCld}$ ) of the amino acid side chain dictates activity profiles and inactivation behavior of Clds. ${ }^{10,11,14}$

Crystal growth of hydrogenated CCld in quartz capillaries was facilitated by applying the method of microseeding. Crystals formed within 5-10 days. Hydrogen/deuterium exchange and change of $\mathrm{pH}$ from 6.5 to $\mathrm{pD} 9.4$ was achieved by repeated crystallization buffer exchange. The dimensions of the investigated diamond shaped crystal were approximately $2.0 \times$ $1.0 \times 0.4 \mathrm{~mm}$. The ratio of crystal volume to asymmetric unit volume was calculated to be 60 , a value underlining the challenging character of the experiment. ${ }^{40}$ The characterization of the heme ligand and determination of the protonation states of amino acid residues (i.e., Lys92, Arg104, Arg105, His114, Arg127, His131, Glu167) were expected to assist a rationalization of the inactivity of the enzyme at this $\mathrm{pH}$. This 
experiment yielded the 54th protein structure solved by neutron crystallography (Protein Data Bank, May 2017) and the first oxidized chlorite dismutase structure collected at room temperature. Using neutrons, the crystal diffracted to a maximum resolution of $2.35 \AA$, whereas with X-rays it diffracted to $2.0 \AA$. The CCld model was refined against X-ray data alone, followed by joint $\mathrm{X}$-ray and neutron refinement.

Figure 8a shows that $\mathrm{N}_{\delta} 1$ of His114 is protonated and in hydrogen bonding distance (i.e., $2.75 \AA$ ) to $\mathrm{O}_{\varepsilon} 1$ of Glu167. The deprotonated $\mathrm{N}_{\varepsilon} 2$ of His114 is at $2.12 \AA$ from the heme iron and serves as proximal ligand. Comparing the His $114 \mathrm{~N}_{\varepsilon} 2$ to iron distances of all structures in complex with endogenous ligands $\mathrm{H}_{2} \mathrm{O}$ or $\mathrm{OH}^{-}$, it can be summarized that they increase in the order X-ray crystallography $\left(\mathrm{H}_{2} \mathrm{O}, 100 \mathrm{~K}\right.$, synchrotron) < Neutron crystallography $\left(\mathrm{OH}^{-}\right)<\mathrm{X}$-ray crystallography $\left(\mathrm{OH}^{-}\right.$, $100 \mathrm{~K}$, synchrotron) < X-ray crystallography $\left(\mathrm{OH}^{-}\right.$, room temperature, in-house source) (Table 2).

Further, $\mathrm{O}_{\varepsilon} 2$ of Glu167 is hydrogen bonded to $\mathrm{N}_{\zeta}$ of Lys92 which in turn makes hydrogen bonding contacts with the heme propionate at position 6 . At the backbone nitrogen of Tyr61, there is no nuclear density observable indicating that the hydrogen is either not easily accessible or that it is involved in a hydrogen bond with the heme propionate at position 7 (Figure $8 \mathrm{~b})$. Both situations could hinder its exchange for deuterium. The hydroxyl group of Tyr61 is in hydrogen bonding distance to the guanidinium group of Arg104; however, nuclear density clearly reveals an involvement of Tyr61 in a hydrogen bond to W506, which is coordinated by O1D of propionate 6 (Figure $8 \mathrm{~b}$ ). Protonated $\mathrm{N}_{\eta} 1$ of $\operatorname{Arg} 105$ is $2.99 \AA$ away from the backbone oxygen of Tyr61.

Most importantly, at $\mathrm{pD} 9.4 \mathrm{Arg} 127$ is fully protonated and $\mathrm{N}_{\varepsilon}$ of this residue is at a distance of $2.59 \AA$ from W502, engaged in a hydrogen bond. Supported by spectroscopic measurements, the nature of the distal heme ligand was characterized to be an $\mathrm{OH}^{-}$ at the studied $\mathrm{pH}$, with an average distance of the oxygen to the iron atom of $2.33 \AA$, longer than expected, therefore, either due to the coexistence of both $6 \mathrm{cHS}$ and LS hydroxo-complexes observed at room temperature or to the photoreduction since also $\mathrm{OH}^{-}$is not a specific ligand of ferrous heme. Comparing all CCld structures in complex with $\mathrm{OH}^{-}$, the ligand-to-iron distance increases in the order neutron crystallography $<\mathrm{X}$-ray crystallography (in-house source) < X-ray crystallography (synchrotron), reflecting the correlation between ligand distance and the reducing power of the applied radiation.

His131 is another critical amino acid residue as it is strictly conserved among functional chlorite dismutases, and its side chain is found at an important position toward the intramolecular channel described above (Figure 7c, left). Three water molecules (W503, W504, W505) form a hydrogen bonding network that spans the His131 side chain and both heme propionates (Figure $7 \mathrm{c}$, right). All three waters can be clearly identified in all obtained density maps (neutron and X-ray). Notably, the signals for the room temperature measurement with neutrons are distinct, with B-factors comparable to protein atoms, suggesting that these water molecules are tightly bound. This in turn emphasizes their important functional role in properly positioning the heme propionate groups.

\section{DISCUSSION}

Chlorite dismutase from Cyanothece sp. PCC7425 is a dimeric representative of clade 2 functional Clds and represents the first protein of this clade which has been comprehensively characterized regarding structure-function relationships. Similar to its characterized homologues (e.g., NdCld, DaCld, Cld from GR-1, KpCld), it is capable of efficiently converting chlorite into chloride and molecular oxygen, the reaction being strongly dictated by $\mathrm{pH}$. The (increasingly incomplete) substrate turnover is significantly slowed down with rising $\mathrm{pH}$. In this work, we have focused on the elucidation of the impact of $\mathrm{pH}$ on structure and the molecular mechanism of chlorite degradation by CCld.

3.1. Impact of $\mathrm{pH}$ on the Active Site Architecture of CCld. Spectroelectrochemical studies revealed that the reduction potential $E^{\circ \prime}$ of the $[\mathrm{Fe}(\mathrm{III}) / \mathrm{Fe}(\mathrm{II}]$ couple of CCld at $\mathrm{pH} 5.0$ is $-82.5 \mathrm{mV}$, which is significantly higher compared to plant type heme $b$ peroxidases like horseradish peroxidase (HRP) $(\sim-260$ $\mathrm{mV})$. This reflects the more hydrophilic distal heme pocket of HRP that stabilizes the ferric state. In CCld, $E^{\circ \prime}$ undergoes a decrease of $-90 \mathrm{mV}$ between $\mathrm{pH} 5.0(-82.5 \mathrm{mV})$ and $\mathrm{pH} 10.0$ $(-172.7 \mathrm{mV})$. A main contribution to this modulation results from the deprotonation of the distal heme ligand $\mathrm{H}_{2} \mathrm{O}$ with increasing $\mathrm{pH}$ giving rise to a predominant hydroxo-LS ligand $\left[\nu(\mathrm{Fe}-\mathrm{OH})\right.$ stretching mode at $\left.510 \mathrm{~cm}^{-1}\right]$, which selectively stabilizes $\mathrm{Fe}$ (III)-heme over $\mathrm{Fe}$ (II)-heme for electrostatic as well as coordinative reasons. ${ }^{41}$ In the case of CCld, the $\mathrm{p} K_{\mathrm{a}}$ of this alkaline transition was found to be 8.1 , a value slightly lower than those reported for pentameric chlorite dismutases (DaCld: $8.77^{14}$ IdCld: $8.5 ;^{15}$ chlorite dismutase from the chlorate respiring strain GR-1:8.2 $2^{42}$ ).

The redox properties of a heme protein are determined by (i) the proximal heme ligand and its noncovalent interactions with other active site residues, (ii) the conformations and interactions of the heme propionates, and (iii) the nature of distal (catalytic) residues and their interactions with both the protein matrix and the solvent. In Clds, a His serves as proximal heme ligand. Studying ferrous CCld, resonance Raman spectroscopy revealed a high $\nu(\mathrm{Fe}-\mathrm{Im})$ frequency $\left(231 \mathrm{~cm}^{-1}\right)$ that is in agreement with the distance $(2.09 \pm 0.03 \AA)$ between the heme iron and the His $114 \mathrm{~N}_{\varepsilon} 2$ found in the X-ray structure obtained at $\mathrm{pH}$ 6.5. It shows that the proximal His114 is H-bonded to the nearby Glu167 residue and thereby obtains a significant imidazolate character, similar to that observed in heme peroxidases. ${ }^{43}$ However, unlike the heme containing peroxidases, the $\nu(\mathrm{Fe}-$ $\mathrm{Im})$ frequency does not vary at basic $\mathrm{pH}$. In fact, for peroxidases at alkaline $\mathrm{pH}$, a downshift of the $\nu(\mathrm{Fe}-\mathrm{His})$ frequency is observed due to a weakening of the $\mathrm{H}$-bond interaction. ${ }^{44}$

The neutron structure of CCld nicely demonstrates the Cldtypical conserved and rigid proximal $\mathrm{H}$-bonding network (Figure 8). It shows that the deprotonated $\mathrm{N}_{\varepsilon} 2$ of His 114 coordinates the ferric heme iron whereas $\mathrm{N}_{\delta} 1$ of His114 is protonated and hydrogen bonded to $\mathrm{O}_{\varepsilon} 1$ of Glu167. Further, $\mathrm{O}_{\varepsilon} 2$ of Glu167 is H-bonded to $\mathrm{N}_{\zeta}$ of Lys92, which in turn makes hydrogen bonding contacts with the heme propionate at position 6 . Except for the distance between the heme iron and $\mathrm{N}_{\varepsilon} 2$ of His114, the lengths of these conserved hydrogen bonds are only very slightly modulated by $\mathrm{pH}$ and the presence of distal ligands (Table 2).

Participation of heme propionates in this network is also underlined by the intense propionate bending band at $370 \mathrm{~cm}^{-1}$ $\left(361 \mathrm{~cm}^{-1}\right.$ for the ferrous form), suggesting a moderate hydrogen bond interaction between the propionate substituents and nearby residues. ${ }^{45}$ Besides interaction of propionate 6 with Lys92, the neutron structure additionally shows that Tyr61, which is connected to propionate 7 via its backbone nitrogen, makes strong $\mathrm{H}$-bonding contacts to propionate 6 via a conserved water molecule (W506). Moreover, the electronic state of the heme cofactor is further influenced by the hydrogen 
bonding network built by His131 and three conserved waters (W503, W504, and W505), spanning from one propionate to the other (Figure $7 \mathrm{c}$ ).

These H-bonding interactions stabilize CCld in the ferric state at all $\mathrm{pH}$ values studied, although this stabilizing effect is more pronounced at alkaline $\mathrm{pH}$ (see above). Around the (acidic) $\mathrm{pH}$ optimum, the resting ferric heme iron participates in a distal $\mathrm{H}$ bonding network that includes the metal ion, W501, W502, conserved Arg127 in "out" conformation and Gln74 (Figure 7b). Distance analyses based on both the X-ray structure at $\mathrm{pH} 8.5$ and the neutron structure at $\mathrm{pH} 9.0$, indicate that deprotonation of W501 at alkaline $\mathrm{pH}$ shortens the distance to the heme iron in agreement with the formation of the $\mathrm{Fe}-\mathrm{OH}$ ligation (highlighted by RR at room temperature). Deprotonation of W501 also significantly weakens or even breaks the interaction between $\mathrm{OH}^{-}$and W502 and simultaneously strengthens the interaction between W502 and Arg127 (Table 2). The interaction between Arg127 and Gln74 is not affected by the alkaline transition.

One of the main questions of the present study was the role of conserved Arg127 in catalysis and whether its protonation status modulates the rate and extent of chlorite degradation. In this work, we could obtain neutron and X-ray diffraction data from the same $\mathrm{H} / \mathrm{D}$ exchanged crystal at $\mathrm{pH}$ 9.0. Therefore, both data sets could be simultaneously refined (joint neutron/X-ray refinement), which can compensate for the increased number of parameters that must be refined in the neutron structure. This is due to the addition of hydrogens atoms into the structure essentially doubling the number of atoms that are present in refinement compared to a typical X-ray structure.

For H/D exchanged samples, phenix.refine automatically determines such sites and performs constrained occupancy refinement, constraining the sum of occupancies of $\mathrm{H}$ and $\mathrm{D}$ to one. For Arg127, phenix.refine calculates occupancies of exchangeable $H / D$ in the side chain for chain $A$ of 1 and for chain $\mathrm{B}$ of 0.97 . Control refinements setting the $\mathrm{D}_{\eta} 22$ and $\mathrm{H}_{\eta} 22$ simultaneously to zero, thereby mimicking a deprotonated state, did not result in a positive density peak at this position. These data clearly suggest that $\mathrm{Arg} 127$ is protonated at $\mathrm{pH} 9.0$ and rule out that it may serve as distal base and dictate the activity profile of CCld. This is also underlined by recently conducted studies about the $\mathrm{p} K_{\mathrm{a}}$ value of Arg which conclude that the guanidinium moiety is virtually always charged in a protein, even in hydrophobic core regions and pockets. ${ }^{46,47}$

3.2. Impact of Ligand Binding on the Structure of the Heme Cavity. Elucidation of the crystal structures of HS and LS complexes studied at $\mathrm{pH} 6.5$ demonstrate that the addition of a ligand, irrespective of its nature, eliminates W501 but not W502 from the heme cavity and keeps Arg127 in the "out" conformation (Figure S13). The binding of the HS ligand fluoride does not induce obvious rearrangements of the distal $\mathrm{H}$ bonding network (Figure S13a, Table 2). By contrast, binding of the LS ligand isothiocyanate (Figure S13b) results in (i) a significantly reduced distance between the nitrogen atom of the ligand and the heme iron with respect to the water or hydroxoligands, and in (ii) weakening of the H-bond between the nitrogen atom and W502 which in the complex is closer to Arg127 (Table 2). For DFT calculations, the isothiocyanate complex [Por $\left.\cdots \mathrm{Fe}(\mathrm{III})-{ }^{-} \mathrm{NCS}\right]$ structure of pentameric AoCld (PDB: 2VXH) was used to construct a model of the enzymesubstrate complex [Por $\left.\cdots \mathrm{Fe}(\mathrm{III})-{ }^{-} \mathrm{OClO}\right]$ before $\mathrm{O}-\mathrm{Cl}$ bond cleavage. ${ }^{48}$ However, any conclusions drawn from these studies should carefully consider that in the AoCld X-ray crystal structure the distal Arg is found in the "in" conformation, thereby displacing a potential bridging water (W502 in CCld) between ligand and distal Arg.

The interaction between ligands, the solvent and the distal protein matrix was also probed by RR spectroscopy. Principally, the absorption maximum of the CT1 band is a sensitive probe of the interaction of fluoride with distal amino acid residues. It redshifts when the ligand acts as an H-bond acceptor, since the interaction between the $p$ orbitals of the ligand and the iron $\mathrm{d} \pi$ orbitals decreases the energy of the latter. ${ }^{30,31}$ In CCld, the low energy of the CT1 band, together with the low frequency of the $\nu\left(\mathrm{Fe}-\mathrm{F}^{-}\right)$stretch, indicate the presence of strong $\mathrm{H}$-bonding interactions supporting the X-ray crystal structure depicted in Figure S13a. Fluoride serves as H-bond acceptor for W502, which in turn is H-bonded to Arg127. This finding is supported by $\mathrm{RR}$ spectra of the $\mathrm{Fe}$ (II)-CO complex, which reveal very moderate polar interactions of carbon monoxide with the distal protein matrix. $\mathrm{CO}$ is not able to interact with water and the Arg127 in the "out" conformation is positioned too far to enable direct contact.

The hypothesis that Arg127 may serve as distal base could also be ruled out by determination of association rate constants of cyanide. The $\mathrm{p} K_{\mathrm{a}}$ of $\mathrm{HCN}$ is 9.14 and, typically, the anionic form $\left(\mathrm{CN}^{-}\right)$binds to the ferric heme protein. In heme peroxidases, a basic amino acid, typically histidine, acts as a proton acceptor forming the anionic ligand that binds to the ferric state. Thus, formation of the LS complex depends on the corresponding $\mathrm{p} K_{\mathrm{a}}$ of the distal histidine. ${ }^{49}$ In the case of functional Clds, the observed $\mathrm{pH}$ dependence clearly underlines that these enzymes lack a distal base that supports deprotonation of HCN. Between $\mathrm{pH} 5.0$ and 8.0, the apparent bimolecular rate constant of cyanide binding to ferric CCld strictly increased with increasing $\mathrm{pH}$ and the ionization of HCN (Figure 5). Accordingly, both the obtained neutron structure of CCld combined with kinetic information on cyanide binding clearly refute the hypothesis that Arg127 acts as a base and dictates the $\mathrm{pH}$ dependence of chlorite degradation.

3.3. Molecular Mechanism of Chlorite Degration. It has been demonstrated previously by isotope-labeling experiments that both oxygen atoms in the evolved $\mathrm{O}_{2}$ derive from chlorite and that the reaction stoichiometry (chlorite:oxygen) is $1: 1{ }^{2}$ Finally, based on experimental studies on pentameric Clds ${ }^{6,10-17}$ and theoretical studies, ${ }^{48}$ two mechanisms were proposed that both involve a (heterolytic or homolytic) $\mathrm{O}-\mathrm{Cl}$ bond cleavage in the [Por $\left.\cdots \mathrm{Fe}(\mathrm{III})-^{-} \mathrm{OClO}\right]$ complex leading to a $\mathrm{ClO}$ fragment (hypochlorous acid or chlorine monoxide) and a high-valent oxoiron(IV) intermediate (Compound I or Compound II).

Studying pre-steady-state kinetics of $\mathrm{NdCld}^{11,12}$ and $\mathrm{DaCld}^{2,14}$ was so far hampered by the fact that (i) the reaction with chlorite proceeds too fast to be tracked by the stopped-flow technique and that (ii) the spectral transitions were ambiguous and thus difficult to interpret. By contrast, the spectral features of dimeric CCld in its various oxidation states are much more pronounced, thus allowing their interconversions during chlorite degradation to be followed.

From studies on heme peroxidases and catalases it is known that $\left(\mathrm{HOCl} /{ }^{-} \mathrm{OCl}\right)$ functions as a two-electron oxidant of heme peroxidases thereby rapidly producing Compound $\mathrm{I}^{23,24}$ At biologically relevant $\mathrm{pH}$, hypochlorous acid is a strong twoelectron oxidant $\left[E^{\circ}\left(\mathrm{HOCl}, \mathrm{H}^{+} / \mathrm{Cl}^{-}, \mathrm{H}_{2} \mathrm{O}\right)=1280 \mathrm{mV}\right.$ at $\mathrm{pH}$ 7.0 and $1490 \mathrm{mV}$ at $\mathrm{pH} 0.0] .{ }^{50}$ As a consequence, it mediates the two-electron oxidation of lactoperoxidase (LPO) or myeloperoxidase $(\mathrm{MPO})^{51}$ to the corresponding Compound I state. This applies also to peracetic acid $\left[E^{\circ \prime}\left(\mathrm{CH}_{3} \mathrm{COOOH}, \mathrm{H}^{+} /\right.\right.$ 
$\left.\mathrm{CH}_{3} \mathrm{COO}^{-}, \mathrm{H}_{2} \mathrm{O}\right)=1636 \mathrm{mV}$ at $\left.\mathrm{pH} 6.0\right] .{ }^{10,52}$ Here, we could demonstrate that CCld follows the same reaction. Hypochlorite rapidly oxidizes the ferric enzyme to Compound I which is characterized by about $50 \%$ hypochromicity at the Soret maximum and a distinct band at $650 \mathrm{~nm}$ (Scheme 1, (4)).

Scheme 1. Proposed Main (Highlighted in Green) and Side Reactions (Highlighted in Blue) of Ferric CCld with Chlorite

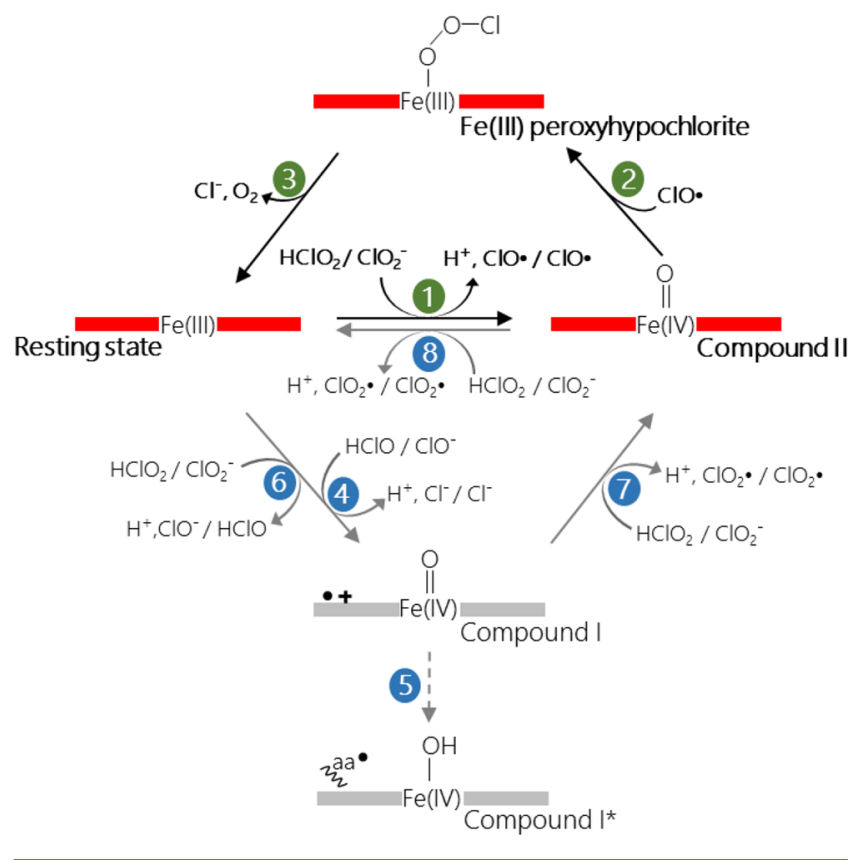

Compound I slowly shifts to an intermediate with spectral features similar to Compound II which is better defined as Compound $\mathrm{I}^{*}$ having the porphyryl radical quenched by electrons spent by the protein matrix (Scheme 1, (5)). This internal (unspecific) electron transfer is increased with increasing $\mathrm{pH}$ which was also seen with Compound I of pentameric DaCld produced by peracetic acid. ${ }^{13}$ For DaCld, freeze-quench EPR confirmed the presence of an uncoupled protein-based radical formed upon decay of Compound I to Compound $\mathrm{I}^{*}$. $^{13}$

Importantly, even in the presence of excess $\left(\mathrm{HOCl} /{ }^{-} \mathrm{OCl}\right)$, neither with CCld nor with $\mathrm{DaCld}$ could $\mathrm{O}_{2}$ formation be measured polarographically. This clearly contradicts an efficient rebound mechanism between Compound I and hypochlorite as described by Reaction IV. This is also underlined by the fact that Compound I formation mediated by chlorite (which must be accompanied by generation of $\mathrm{HOCl}$ ) has never been detected with pentameric chlorite dismutases by using UV-vis stoppedflow spectroscopy. Moreover, heterolytic cleavage of chlorite was ruled out by DFT calculations due to the absence of spin localized at the porphyrin macrocycle and an unfavorable high energy barrier. $^{48}$

In contrast, mixing of dimeric CCld with chlorite in the stopped-flow apparatus leads to the formation of Compound II (Soret maximum at $418 \mathrm{~nm}$, two prominent bands at 528 and $551 \mathrm{~nm}$ ) within milliseconds (Scheme 1, (1)). Chlorite is a weaker two-electron oxidant compared to $\mathrm{HOCl} /{ }^{-} \mathrm{OCl}$. Its standard reduction potential for the redox couple $\left(\mathrm{HClO}_{2}, 2 \mathrm{H}^{+} /\right.$

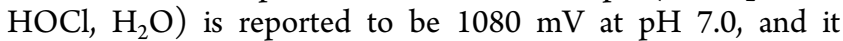
increases with $88 \mathrm{mV}$ per $\mathrm{pH}$ unit with decreasing $\mathrm{pH}$ (being 1256 at $\mathrm{pH} 5.0$ and $1645 \mathrm{mV}$ at $\mathrm{pH} 0.0) .{ }^{53}$ Chlorite is well-known to mediate Compound I formation in horseradish peroxidase
(HRP) $\left[E^{\circ \prime}(\mathrm{Fe}(\mathrm{III}) / \mathrm{Fe}(\mathrm{II}))=-310 \mathrm{mV} ; E^{\circ \prime}\right.$ (Compound I/ ferric HRP $)=920 \mathrm{mV}$ at $\mathrm{pH} 7.0]^{24,54}$ Under acidic conditions, oxidation of HRP by chlorite becomes more favorable because of the divergent $\mathrm{pH}$ dependencies of both redox couples. The potential of the couple (Compound I/ferric HRP) increases with $59 \mathrm{mV}$ per decreasing $\mathrm{pH}$ unit. ${ }^{54}$ In contrast to $\mathrm{HRP}$, chlorite is unable to mediate Compound I formation of $\mathrm{MPO}\left[E^{\circ \prime}(\mathrm{Fe}(\mathrm{III}) /\right.$ $\mathrm{Fe}(\mathrm{II}))=+5 \mathrm{mV}$; $E^{\circ \prime}$ (Compound $\mathrm{I} /$ ferric MPO) $=1160 \mathrm{mV}$ at $\mathrm{pH} 7.0]^{55,56}$ or bovine LPO $\left[E^{\circ \prime}(\mathrm{Fe}(\mathrm{III}) / \mathrm{Fe}(\mathrm{II}))=-183 \mathrm{mV}\right.$; $E^{\circ \prime}$ (Compound I/ferric HRP) $=1090 \mathrm{mV}$ at $\left.\mathrm{pH} 7.0\right]^{57,58}$ Although we do not know $E^{\circ \prime}$ (Compound I/ferric) of CCld, it is reasonable to assume that the two-electron oxidation of CCld by chlorite is thermodynamically unfavorable. As already discussed above, due to the hydrophobic heme cavity, $E^{\circ \prime}[\mathrm{Fe}(\mathrm{III}) / \mathrm{Fe}(\mathrm{II})]$ of CCld is high (in between $E^{\circ \prime}$ of LPO and MPO), which suggests that also $E^{\circ \prime}$ (Compound I/ferric CCld) exhibits values comparable to LPO and MPO $(>1100 \mathrm{mV})$. By contrast, the one-electron oxidation of ferric CCld by chlorite should be thermodynamically feasible since (in analogy to heme peroxidases) $E^{\circ \prime}$ (Compound II/ferric CCld) $<E^{\circ \prime}$ (Compound I/ ferric CCld) and Compound II will be more stable in a hydrophobic cavity compared to Compound I. This is also indicated by computational studies. ${ }^{48}$

Due to increasing $E^{\circ \prime}$ values of the redox couple $\left(\mathrm{HClO}_{2}\right.$, $2 \mathrm{H}^{+} / \mathrm{HOCl}, \mathrm{H}_{2} \mathrm{O}$ ) with decreasing $\mathrm{pH}$, the two-electron oxidation of ferric CCld might become feasible in the acidic region (Scheme 1, (6)). Indeed, upon mixing ferric CCld with chlorite at $\mathrm{pH} 5.0$, we monitored some hypochromicity in the Soret absorbance within the first milliseconds before Compound II is formed (Figure 4a). This might indicate formation of Compound I to a certain extent. Nevertheless, at $\mathrm{pH}>5.0$ ferric CCld is converted directly to Compound II.

In the time course of chlorite degradation, Compound II is the dominating redox intermediate at all $\mathrm{pH}$ values. It should be mentioned that the spectral properties of Compound II are completely different from those of the LS (cyanide, isothiocyanate, hydroxide) complexes (421-538 nm, 414-532 nm, 414$540 \mathrm{~nm}$, respectively) ruling out that the observed dominating intermediate during turnover represents [Por $\cdots \mathrm{Fe}$ (III)$\mathrm{OOCl}^{-}$], i.e. the reaction product of the rebinding step (Scheme $1,(2))$. According to computational studies, this intermediate can be considered as a transient (short-lived) LS complex of ferric Cld. ${ }^{48}$

At all $\mathrm{pH}$ values, Compound II is formed immediately upon mixing ferric CCld with chlorite, whereas the total time for chlorite degradation (followed at $280 \mathrm{~nm}$ ) significantly increases with increasing $\mathrm{pH}$. A mechanistic explanation of this behavior is yet to be found since the presented structural data disprove the hypothesis that the distal Cld-typical Arg dictates the $\mathrm{pH}$ dependence. As outlined above, it is protonated at all studied $\mathrm{pH}$ values (even in the presence of anionic ligands) and its orientation in crystal structures is always "out". The dominating "out" conformation is also supported by RR data that suggest weak interactions of the $\mathrm{CO}$ ligand with the protein matrix. However, we do not want to dispute the hypothesis that Arg127 is flexible and can adopt the "in" conformation in solution during enzyme turnover.

Based on these findings we propose the following reaction mechanism. The reaction cycle of dimeric CCld is initiated by binding of the anionic substrate $\left(\mathrm{p} K_{\mathrm{a}}=1.72\right)$ to the $\mathrm{Fe}(\mathrm{III})$ center which occurs spontaneously and independent of Arg. ${ }^{11}$ At this step, Arg is in the "out" conformation and seems to be relevant for chlorite recognition only. ${ }^{9}$ The resulting enzyme- 
substrate complex [Por $\left.\cdots \mathrm{Fe}(\mathrm{III})-{ }^{-} \mathrm{OClO}\right]$ is either hydrogen bonded to W502 as suggested by the CCld-isothiocyanate complex [Por...Fe(III) - ${ }^{-} \mathrm{NCS}$ ] or directly to Arg127, which in the "in" conformation would displace W502. As suggested by computational studies, in the "in" conformation both oxygen atoms of chlorite act as H-bond acceptors for the Arg. By homolytic cleavage chlorine monoxide and Compound II are formed (Scheme 1, (1)). Our stopped-flow studies clearly show that Compound II formation is extremely fast between $\mathrm{pH} 5.0$ and 9.0 suggesting that the rate of homolytic bond cleavage is independent of $\mathrm{pH}$. This might suggest that the following rebound step (Scheme 1, (2)) is responsible for the observed $\mathrm{pH}$ dependence. These findings also rule out that there is any mechanistic difference in the replacement of either W501 (at acidic $\mathrm{pH})$ or its deprotonated version (at alkaline $\mathrm{pH})\left(\mathrm{p} K_{\mathrm{a}}=\right.$ 8.1) that could lead to the observed $\mathrm{pH}$ dependence.

With increasing $\mathrm{pH}$, the $\mathrm{O}-\mathrm{O}$ bond formation apparently becomes inefficient and the rate of chlorite degradation decreases significantly. Rebinding of Compound II and chlorine monoxide needs rotation of the latter and rearrangements of $\mathrm{H}$-bonds with $\operatorname{Arg} 127$ to support $\mathrm{O}-\mathrm{O}$ bond formation which-according to computational studies-is a very fast process. $^{48}$ Finally, to facilitate the departure of the chloride anion from the resulting LS complex [Por $\cdots \mathrm{Fe}(\mathrm{III})-\mathrm{OOCl}^{-}$], the $\mathrm{H}$-bonds between the Arg and the two oxygen atoms are required to rearrange again to the terminal $\mathrm{Cl}$ atom, an event which might provide the stabilization for the leaving negatively charged chloride anion (Scheme 1, (3)).

Besides the decrease of the rate of chlorite degradation, Clds become inactivated at alkaline $\mathrm{pH}$. As a consequence, the degradation of higher amounts of chlorite is incomplete under these conditions. This is also the case for CCld. ${ }^{20}$ Based on studies on pentameric Clds and a proposed heterolytic cleavage of chlorite, it was hypothesized that hypochlorite is responsible for the irreversible inactivation of the enzyme. ${ }^{11}$ Inefficient rebinding of hypochlorite to Compound I was proposed to lead to the release of $\left(\mathrm{HOCl} /{ }^{-} \mathrm{OCl}\right)$ which oxidatively modifies both the heme cofactor and the protein. This was demonstrated by addition of hypochlorite traps. However, it is not possible to exclude that other chlorine species (chlorine monoxide or the observed byproduct chlorine dioxide, see below) also react with the trapping agents that were applied in the cited study. It is reasonable to assume that under suboptimal conditions for the rebound reaction the postulated intermediate chlorine monoxide escapes from the reaction sphere and promotes enzyme inactivation.

The present study also shows that chlorine dioxide is a byproduct of chlorite degradation. Typically, it derives from the one-electron oxidation of chlorite by redox intermediates like Compound I and Compound II of heme peroxidases. ${ }^{24}$ The standard reduction potential of the couple $\left(\mathrm{ClO}_{2} / \mathrm{ClO}_{2}{ }^{-}\right)$has a value of $934 \mathrm{mV}$ and is independent of $\mathrm{pH}$ above $\mathrm{pH} 2.0 .{ }^{59}$ Both Compound I and II of CCld could be able to mediate the oxidation of chlorite to chlorine dioxide. As mentioned above, at acidic $\mathrm{pH}$, some Compound I formation might occur as a side reaction. Its reduction to Compound II would generate chlorine dioxide (Scheme 1, (7)). Moreover, at excess of chlorite and/or under nonoptimal conditions for the rebound reaction, chlorite can compete with chlorine monoxide and act as electron donor for Compound II. Thereby, chlorine monoxide is eliminated from the reaction sphere and chlorine dioxide is produced (Scheme 1, (8)). These reactions and the release of the generated chlorine species might contribute to the $\mathrm{pH}$ dependence and enzyme inactivation at increasing $\mathrm{pH}$ values.

However, further investigations are definitely necessary to elucidate the exact mechanism of the $\mathrm{pH}$ dependence of chlorite degradation. The present study unequivocally demonstrates that CCld is an excellent model enzyme to study these reactions. It is possible to grow high-quality crystals at various $\mathrm{pH}$ to obtain high-resolution X-ray and neutron structures. Most importantly, it allows assignment of all relevant redox intermediates according to their spectral features and study of the kinetics of their interconversion by multimixing stopped-flow spectroscopy.

\section{ASSOCIATED CONTENT}

Supporting Information

The Supporting Information is available free of charge on the ACS Publications website at DOI: 10.1021/acscatal.7b01749.

Full experimental details and additional figures and tables discussed in the text (PDF)

$\mathrm{X}$-ray (room temperature) (CIF)

CCld in complex with isothiocyanate (CIF)

CCld at pH 6.5 (in complex with $\mathrm{H}_{2} \mathrm{O}$ ) (CIF)

CCld in complex with fluoride (CIF)

Neutron (CIF)

CCld at $\mathrm{pH} 8.5$ (CIF)

\section{AUTHOR INFORMATION}

\section{Corresponding Author}

*E-mail: christian.obinger@boku.ac.at. Phone: +43-1-4765477273. Fax: +43-1-47654-77059.

ORCID $\odot$

Paul G. Furtmüller: 0000-0002-1199-2469

Giulietta Smulevich: 0000-0003-3021-8919

Christian Obinger: 0000-0002-7133-3430

\section{Author Contributions}

(I.S. and G.M.) These authors contributed equally.

\section{Notes}

The authors declare no competing financial interest.

\section{ACKNOWLEDGMENTS}

This project was supported by the Austrian Science Fund, FWF [Doctoral program BioToP-Molecular Technology of Proteins (W1224) and the projects P25270 and P22276] and the Federal Ministry of Economy, Family and Youth through the initiative "Laura Bassi Centres of Expertise", funding the Center of Optimized Structural Studies, No. 253275. Research at the Spallation Neutron Source (SNS) at ORNL was sponsored by the Scientific User Facilities Division, Office of Basic Energy Sciences, U.S. Department of Energy. We thank Elisabeth Lobner, Christa Jakopitsch, and Rupert Tscheließnig for lab assistance, discussions and assistance in data analysis.

\section{REFERENCES}

(1) Hofbauer, S.; Schaffner, I.; Furtmüller, P. G.; Obinger, C. Biotechnol. J. 2014, 9, 461-473.

(2) Lee, A. Q.; Streit, B. R.; Zdilla, M. J.; Abu-Omar, M. M.; DuBois, J. L. Proc. Natl. Acad. Sci. U. S. A. 2008, 105, 15654-15659.

(3) Shen, J. R. Annu. Rev. Plant Biol. 2015, 66, 23-48.

(4) Goblirsch, B. R.; Streit, B. R.; DuBois, J. L.; Wilmot, C. M. JBIC, J. Biol. Inorg. Chem. 2010, 15, 879-888.

(5) Goblirsch, B. R.; Streit, B. R.; DuBois, J. L.; Wilmot, C. M. Acta Crystallogr., Sect. F: Struct. Biol. Cryst. Commun. 2009, 65, 818-821. 
(6) Kostan, J.; Sjöblom, B.; Maixner, F.; Mlynek, G.; Furtmüller, P. G.; Obinger, C.; Wagner, M.; Daims, H.; Djinović-Carugo, K. J. Struct. Biol. 2010, 172, 331-342.

(7) Keith, J. M.; Abu-Omar, M. M.; Hall, M. B. Inorg. Chem. 2011, 50, $7928-7930$

(8) Fabian, I.; Gordon, G. Inorg. Chem. 1991, 30, 3785-3787.

(9) Sündermann, A.; Reif, M. M.; Hofbauer, S.; Obinger, C.; Oostenbrink, C. Biochemistry 2014, 53, 4869-4879.

(10) Blanc, B.; Mayfield, J. A.; McDonald, C. A.; Lukat-Rodgers, G. S.; Rodgers, K. R.; DuBois, J. L. Biochemistry 2012, 51, 1895-1910.

(11) Hofbauer, S.; Gruber, C.; Pirker, K. F.; Sündermann, A.; Schaffner, I.; Jakopitsch, C.; Oostenbrink, C.; Furtmüller, P. G.; Obinger, C. Biochemistry 2014, 53, 3145-3157.

(12) Hofbauer, S.; Gysel, K.; Bellei, M.; Hagmuller, A.; Schaffner, I.; Mlynek, G.; Kostan, J.; Pirker, K. F.; Daims, H.; Furtmüller, P. G.; Battistuzzi, G.; Djinovic-Carugo, K.; Obinger, C. Biochemistry 2014, 53, 77-89.

(13) Mayfield, J. A.; Hammer, N. D.; Kurker, R. C.; Chen, T. K.; Ojha, S.; Skaar, E. P.; DuBois, J. L. J. Biol. Chem. 2013, 288, 23488-23504.

(14) Streit, B. R.; Blanc, B.; Lukat-Rodgers, G. S.; Rodgers, K. R.; DuBois, J. L. J. Am. Chem. Soc. 2010, 132, 5711-5724.

(15) Stenklo, K.; Danielsson Thorell, H.; Bergius, H.; Aasa, R.; Nilsson, T. JBIC, J. Biol. Inorg. Chem. 2001, 6, 601-607.

(16) Streit, B. R.; DuBois, J. L. Biochemistry 2008, 47, 5271-5280.

(17) van Ginkel, C. G.; Rikken, G. B.; Kroon, A. G.; Kengen, S. W. Arch. Microbiol. 1996, 166, 321-326.

(18) Mlynek, G.; Sjöblom, B.; Kostan, J.; Füreder, S.; Maixner, F.; Gysel, K.; Furtmüller, P. G.; Obinger, C.; Wagner, M.; Daims, H.; Djinović-Carugo, K. J. Bacteriol. 2011, 193, 2408-2417.

(19) Celis, A. I.; Geeraerts, Z.; Ngmenterebo, D.; Machovina, M. M.; Kurker, R. C.; Rajakumar, K.; Ivancich, A.; Rodgers, K. R.; LukatRodgers, G. S.; DuBois, J. L. Biochemistry 2015, 54, 434-446.

(20) Schaffner, I.; Hofbauer, S.; Krutzler, M.; Pirker, K. F.; Bellei, M.; Stadlmayr, G.; Mlynek, G.; Djinovic-Carugo, K.; Battistuzzi, G.; Furtmüller, P. G.; Daims, H.; Obinger, C. Mol. Microbiol. 2015, 96, $1053-1068$.

(21) Hori, H.; Kitagawa, T. J. Am. Chem. Soc. 1980, 102, 3608-3613.

(22) Stein, P.; Mitchell, M.; Spiro, T. G. J. Am. Chem. Soc. 1980, 102, 7795-7797.

(23) Floris, R.; Wever, R. Eur. J. Biochem. 1992, 207, 697-702.

(24) Jakopitsch, C.; Spalteholz, H.; Furtmüller, P. G.; Arnhold, J.; Obinger, C. J. Inorg. Biochem. 2008, 102, 293-302.

(25) Prince, L. A. Anal. Chem. 1964, 36, 613-616.

(26) Chen, T.-H. Anal. Chem. 1967, 39, 804-813.

(27) De Schutter, A.; Correia, H. D.; Freire, D. M.; Rivas, M. G.; Rizzi, A.; Santos-Silva, T.; Gonzalez, P. J.; Van Doorslaer, S. J. Phys. Chem. B 2015, 119, 13859-13869.

(28) Geeraerts, Z.; Rodgers, K. R.; DuBois, J. L.; Lukat-Rodgers, G. S. Biochemistry 2017, 56, 4509-4524.

(29) Freire, D. M.; Rivas, M. G.; Dias, A. M.; Lopes, A. T.; Costa, C.; Santos-Silva, T.; Van Doorslaer, S.; Gonzalez, P. J. J. Inorg. Biochem. 2015, 151, 1-9.

(30) Droghetti, E.; Nicoletti, F. P.; Bonamore, A.; Sciamanna, N.; Boffi, A.; Feis, A.; Smulevich, G. J. Inorg. Biochem. 2011, 105, 1338-1343.

(31) Nicoletti, F. P.; Droghetti, E.; Boechi, L.; Bonamore, A.; Sciamanna, N.; Estrin, D. A.; Feis, A.; Boffi, A.; Smulevich, G. J. Am. Chem. Soc. 2011, 133, 20970-20980.

(32) Battistuzzi, G.; Bellei, M.; Bortolotti, C. A.; Rocco, G. D.; Leonardi, A.; Sola, M. Arch. Biochem. Biophys. 2004, 423, 317-331.

(33) Dong, S.; Niu, J.; Cotton, T. M. Ultraviolet/visible spectroelectrochemistry of redox proteins. In Methods in Enzymology; Kenneth, S., Ed.; Academic Press: San Diego, 1995; Vol. 246, pp 701-732.

(34) Millis, C. D.; Cai, D. Y.; Stankovich, M. D.; Tien, M. Biochemistry 1989, 28, 8484-8489.

(35) Indiani, C.; Santoni, E.; Becucci, M.; Boffi, A.; Fukuyama, K.; Smulevich, G. Biochemistry 2003, 42, 14066-14074.

(36) Meharenna, Y. T.; Doukov, T.; Li, H.; Soltis, S. M.; Poulos, T. L. Biochemistry 2010, 49, 2984-2986.
(37) Petřek, M.; Otyepka, M.; Banáš, P.; Košinová, P.; Koča, J.; Damborský, J. BMC Bioinf. 2006, 7, 316.

(38) Macedo, S.; Pechlaner, M.; Schmid, W.; Weik, M.; Sato, K.; Dennison, C.; Djinović-Carugo, K. J. Synchrotron Radiat. 2009, 16, 191204.

(39) Kwon, H.; Smith, O.; Raven, E.; Moody, P. Acta Crystallogr., Sect. D: Biol. Crystallogr. 2017, 73, 141-147.

(40) Blakeley, M. P.; Hasnain, S. S.; Antonyuk, S. V. IUCrJ 2015, 2, 464-474.

(41) Casalini, S.; Battistuzzi, G.; Borsari, M.; Ranieri, A.; Sola, M. J. Am. Chem. Soc. 2008, 130, 15099-15104.

(42) Hagedoorn, P. L.; de Geus, D. C.; Hagen, W. R. Eur. J. Biochem. 2002, 269, 4905-4911.

(43) Zamocky, M.; Hofbauer, S.; Schaffner, I.; Gasselhuber, B.; Nicolussi, A.; Soudi, M.; Pirker, K. F.; Furtmüller, P. G.; Obinger, C. Arch. Biochem. Biophys. 2015, 574, 108-119.

(44) Smulevich, G., Howes, B. D., Droghetti, E. Structural and functional properties of heme-containing peroxidases: a resonance Raman perspective for the superfamily of plant, fungal and bacterial peroxidases In Heme Peroxidases; Raven, E., Dunford, B., Eds.; The Royal Society of Chemistry: Cambridge, U.K., 2015; pp 61-98.

(45) Cerda-Colón, J. F.; Silfa, E.; López-Garriga, J. J. Am. Chem. Soc. 1998, 120, 9312-9317.

(46) Fitch, C. A.; Platzer, G.; Okon, M.; Garcia-Moreno E., B.; McIntosh, L. P. Protein Sci. 2015, 24, 752-761.

(47) Harms, M. J.; Schlessman, J. L.; Sue, G. R.; Garcia-Moreno E., E. B. Proc. Natl. Acad. Sci. U. S. A. 2011, 108, 18954-18959.

(48) Sun, S.; Li, Z. S.; Chen, S. L. Dalton Trans. 2014, 43, 973-981.

(49) Araiso, T.; Dunford, H. B. J. Biol. Chem. 1981, 256, 10099-10104.

(50) Arnhold, J.; Monzani, E.; Furtmüller, P. G.; Zederbauer, M.; Casella, L.; Obinger, C. Eur. J. Inorg. Chem. 2006, 2006, 3801-3811.

(51) Furtmüller, P. G.; Burner, U.; Jantschko, W.; Regelsberger, G.; Obinger, C. Redox Rep. 2000, 5, 173-178.

(52) Awad, M. I.; Denggerile, A.; Ohsaka, T. J. Electrochem. Soc. 2004, 151, E358-E363.

(53) Epstein, I. R.; Kustin, K. J. Phys. Chem. 1985, 89, 2275-2282.

(54) Hayashi, Y.; Yamazaki, I. J. Biol. Chem. 1979, 254, 9101-9106.

(55) Arnhold, J.; Furtmüller, P. G.; Obinger, C. Redox Rep. 2003, 8, 179-186.

(56) Arnhold, J.; Furtmüller, P. G.; Regelsberger, G.; Obinger, C. Eur. J. Biochem. 2001, 268, 5142-5148.

(57) Furtmüller, P. G.; Arnhold, J.; Jantschko, W.; Zederbauer, M.; Jakopitsch, C.; Obinger, C. J. Inorg. Biochem. 2005, 99, 1220-1229.

(58) Jakopitsch, C.; Pirker, K. F.; Flemmig, J.; Hofbauer, S.; Schlorke, D.; Furtmüller, P. G.; Arnhold, J.; Obinger, C. J. Inorg. Biochem. 2014, $135,10-19$.

(59) Klaning, U. K.; Sehested, K.; Holcman, J. J. Phys. Chem. 1985, 89, 760-763. 